\title{
Human Astrocytes Transfer Aggregated Alpha-Synuclein via Tunneling Nanotubes
}

\author{
Jinar Rostami, ${ }^{1}$ Staffan Holmqvist, ${ }^{3,4,5}$ Veronica Lindström, ${ }^{1}$ Jessica Sigvardson, ${ }^{6}$ Gunilla T Westermark, ${ }^{2}$ \\ Martin Ingelsson, ${ }^{1}$ Joakim Bergström, ${ }^{1}$ Laurent Roybon, ${ }^{3,4,5}$ and Anna Erlandsson ${ }^{1}$ \\ ${ }^{1}$ Molecular Geriatrics, Department of Public Health and Caring Sciences, Rudbeck Laboratory, Uppsala University 75185 Uppsala, Sweden, ${ }^{2}$ Department of \\ Medical Cell Biology, BMC, Uppsala University, 75123 Uppsala, Sweden, ${ }^{3}$ Stem Cell Laboratory for CNS Disease Modeling, Wallenberg Neuroscience \\ Center, Department of Experimental Medical Science, ${ }^{4}$ Strategic Research Area MultiPark, and ${ }^{5}$ Lund Stem Cell Center, Lund University, 22184 Lund, \\ Sweden, and ${ }^{6}$ BioArctic AB, 11251 Stockholm, Sweden
}

Many lines of evidence suggest that the Parkinson's disease (PD)-related protein $\alpha$-synuclein ( $\alpha$-SYN) can propagate from cell to cell in a prion-like manner. However, the cellular mechanisms behind the spreading remain elusive. Here, we show that human astrocytes derived from embryonic stem cells actively transfer aggregated $\alpha$-SYN to nearby astrocytes via direct contact and tunneling nanotubes (TNTs). Failure in the astrocytes' lysosomal digestion of excess $\alpha$-SYN oligomers results in $\alpha$-SYN deposits in the trans-Golgi network followed by endoplasmic reticulum swelling and mitochondrial disturbances. The stressed astrocytes respond by conspicuously sending out TNTs, enabling intercellular transfer of $\alpha$-SYN to healthy astrocytes, which in return deliver mitochondria, indicating a TNTmediated rescue mechanism. Using a pharmacological approach to inhibit TNT formation, we abolished the transfer of both $\alpha$-SYN and mitochondria. Together, our results highlight the role of astrocytes in $\alpha$-SYN cell-to-cell transfer, identifying possible pathophysiological events in the PD brain that could be of therapeutic relevance.

Key words: alpha-synuclein; astrocytes; lysosomes; mitochondria; trans-Golgi; tunneling nanotubes

\section{Significance Statement}

Astrocytes are the major cell type in the brain, yet their role in Parkinson's disease progression remains elusive. Here, we show that human astrocytes actively transfer aggregated $\alpha$-synuclein $(\alpha$-SYN) to healthy astrocytes via direct contact and tunneling nanotubes (TNTs), rather than degrade it. The astrocytes engulf large amounts of oligomeric $\alpha$-SYN that are subsequently stored in the trans-Golgi network region. The accumulation of $\alpha$-SYN in the astrocytes affects their lysosomal machinery and induces mitochondrial damage. The stressed astrocytes respond by sending out TNTs, enabling intercellular transfer of $\alpha$-SYN to healthy astrocytes. Our findings highlight an unexpected role of astrocytes in the propagation of $\alpha$-SYN pathology via TNTs, revealing astrocytes as a potential target for therapeutic intervention.

\section{Introduction}

Cellular inclusions in the brain, often referred to as Lewy bodies and Lewy neurites, are a pathological hallmark for Parkinson's disease (PD) and several other neurodegenerative disorders, including dementia with Lewy bodies and multiple system atrophy

\section{Received April 11, 2017; revised Sept. 20, 2017; accepted 0ct. 11, 2017.}

Author contributions: J.R., S.H., V.L., G.T.W., M.I., J.B., L.R., and A.E. designed research; J.R. performed research; J.S. contributed unpublished reagents/analytic tools; J.R. and A.E. analyzed data; J.R., S.H., V.L., G.T.W., M.I., J.B., L.R., and A.E. wrote the paper.

This work was supported by the Swedish Research Council (L.R., A.E.), Parkinson Foundation, Alzheimer Foundation, Åhlén Foundation, Dementia Association Foundation, Crafoord Foundation, Kockska Foundation, Åke Wiberg Foundation, Lennart and Christina Kalén, Hedlunds Foundation, and Brain Stem-Stem Cell Center of Excellence in Neurology funded by Innovation Fund Denmark. We thank Linn Gallasch and Sofia Söllvander at Uppsala University for their support and Anders Ahlander at the SciLifeLab BioVis Facility, Uppsala University, for technical assistance with TEM.

The authors declare no competing financial interests.
(Spillantini et al., 1998). The inclusions predominantly consist of insoluble fibrillary forms of the $\alpha$-synuclein ( $\alpha$-SYN) protein (Spillantini et al., 1997), but smaller soluble aggregates are also present in the diseased brain. These aggregates, referred to as $\alpha$-SYN oligomers, are particularly neurotoxic (Danzer et al., 2007; Chinta et al., 2010; Winner et al., 2011; Luth et al., 2014; Ogen-Shtern et al., 2016). Although $\alpha$-SYN deposits are primarily found in neurons, they also appear frequently in glial cells at

Correspondence should be addressed to Anna Erlandsson, Department of Public Health and Caring Sciences/ Molecular Geriatrics, Rudbeck Laboratory, Uppsala University, SE-751 85 Uppsala, Sweden. E-mail: anna.erlandsson@pubcare.uu.se.

D0I:10.1523/JNEUROSCI.0983-17.2017

Copyright $\odot 2017$ Rostami et al.

This is an open-access article distributed under the terms of the Creative Commons Attribution License Creative Commons Attribution 4.0 International, which permits unrestricted use, distribution and reproduction in any medium provided that the original work is properly attributed. 
advanced disease stages (Tu et al., 1998; Wakabayashi et al., 2000; Terada et al., 2003; Croisier and Graeber, 2006; Braak et al., 2007). However, the consequences of astrocytic $\alpha$-SYN inclusions for progression and spreading of PD pathology remain unknown.

Being the most abundant glial cell type in the nervous system, astrocytes play an important role in maintaining brain homeostasis (Sofroniew and Vinters, 2010). The complex role of astrocytes in the pathological brain is largely dependent on their release and uptake of substances from the microenvironment that they share with the neurons (Sofroniew and Vinters, 2010). For example, astrocytes confer neuroprotection by removing excessive extracellular glutamate, potassium, and calcium, whereas they produce cytokines and chemokines that could be harmful to neurons if released chronically (Rappold and Tieu, 2010; Sofroniew and Vinters, 2010).

Reactive astrocytes effectively engulf dead cells, synapses, and protein aggregates of amyloid $\beta(\mathrm{A} \beta)$ and $\alpha$-SYN (Chang et al., 2000; Magnus et al., 2002; Sokolowski et al., 2011; Lööv et al., 2012; Chung et al., 2013; Fellner et al., 2013; Jones et al., 2013; Söllvander et al., 2016). Moreover, experimental evidence from in vitro and in vivo studies indicates that $\alpha$-SYN can transfer from cell to cell and thereby contribute to disease progression (Kordower et al., 2008; Li et al., 2008; Desplats et al., 2009; Lee et al., 2010; Danzer et al., 2011; Hansen et al., 2011). Several transfer mechanisms have been suggested, including exocytosis/endocytosis, extracellular vesicle secretion, and prion-like spreading, but many questions remain regarding $\alpha$-SYN spreading and the involvement of various cell types, notably astrocytes (Gousset et al., 2009; Jang et al., 2010; Emmanouilidou et al., 2011).

Tunneling nanotubes (TNTs) are thin protrusions that allow direct physical connections of the plasma membranes between remote cells. The existence of TNTs was described for the first time in 2004 (Rustom et al., 2004). Subsequently, TNTs have been found in numerous cell types, including neurons and glial cells (Zhu et al., 2005; Wang et al., 2012). Their primary function is to transfer cellular components such as organelles, proteins, genetic materials, ions, and small molecules between cells over long distances (Kimura et al., 2013). However, TNTs have also been suggested to be important in pathological conditions by facilitating the intercellular spreading of viruses and pathogenic proteins (Rustom et al., 2004). The smallest TNTs $(<100 \mathrm{~nm}$ in diameter) only contain F-actin, whereas thicker TNTs ( $>100 \mathrm{~nm}$ in diameter) are composed of both F-actin and microtubules and allow cell-to-cell transfer of larger compartments such as organelles (Wang et al., 2011; Sisakhtnezhad and Khosravi, 2015). Therefore, TNT formation can effectively be inhibited by F-actin depolymerization drugs such as latrunculin B (Bukoreshtliev et al., 2009).

Knowledge about the cellular mechanisms behind the initiation and propagation of PD is still very limited. Here, we show that human astrocytes engulf large amounts of $\alpha$-SYN oligomers that are subsequently stored in the trans-Golgi region. The accumulation of $\alpha$-SYN in the astrocytes affects their phagosomallysosomal machinery and induces mitochondrial damage. As a consequence of these stress reactions, the $\alpha$-SYN-containing astrocytes protrude TNTs, which mediate transfer of $\alpha$-SYN aggregates and mitochondria between neighboring cells. Together, our results highlight an unexpected role of astrocytes in the progression of $\alpha$-SYN pathology.

\section{Materials and Methods}

\section{$\alpha$-SYN oligomer generation and labeling}

Recombinant $\alpha$-SYN $(140 \mu \mathrm{M})$ was produced as described previously (Näsström et al., 2011). Monomeric $\alpha$-SYN was incubated with 4-hydroxynonenal (HNE) (Cayman Chemicals) in a HNE: $\alpha$-SYN ratio of 30:1 at $37^{\circ} \mathrm{C}$ for $72 \mathrm{~h}$. SEC-HPLC was performed on a Superose 6 PC 3.2/30 column (GE Healthcare) and revealed a near complete conversion from monomers to oligomers (Fig. 1-1 B, available at https://doi.org/10. 1523/JNEUROSCI.0983-17.2017.f1-1). As an eluent, $20 \mathrm{~mm}$ Tris and $0.15 \mathrm{M} \mathrm{NaCl}, \mathrm{pH} 7.4$, was used at a flow rate of $50 \mu \mathrm{l} / \mathrm{min}$. The $\alpha$-SYN oligomers were labeled with the $\mathrm{Cy} 3^{\mathrm{AM}}$ Antibody Labeling Kit (GE Healthcare, PA33000), the Atto 488 protein labeling kit (Sigma-Aldrich) or pHrodo (Invitrogen, P36600). The pHrodo dye reacts with amine groups on the cell surface and is nonfluorescent at neutral $\mathrm{pH}$, but emits red light at an increasing intensity as the $\mathrm{pH}$ is lowered. For all labeling, the protocols provided with the dye kits were followed and unbound excess Cy3, Atto 488, or pHrodo were removed by filtration in a Zeba spin desalting column (Thermo Scientific) according to the manufacturer's instructions.

Culture of human embryonic stem cell (ESC)-derived astrocytes Human ESC-derived astrocytes were generated as described previously (Holmqvist et al., 2015; Stem Cell Research). The cells were cultured in Advanced DMEM/F12 (Thermo Fisher Scientific, 12634-010) supplied with 1\% FBS (Thermo Fisher Scientific, 10082-147), 1\% penicillin/ streptavidin (Thermo Fisher Scientific, 15140-122), $2 \mu \mathrm{g} / \mathrm{ml}$ heparin (Sigma-Aldrich, H4784), 10\% B27 supplement (Thermo Fisher Scientific, 17504-044), 1\% nonessential amino acids (Merck Millipore, TMS001-C), and 1\% L-glutamine (Thermo Fisher Scientific, 25030024). Cells were passaged using Trypsin-EDTA (Life Technologies). Cells from 90 to $120 \mathrm{~d}$ in vitro (DIV) were used in the study. For experiments, the astrocytes were seeded at a concentration of $1500 \mathrm{cells} / \mathrm{cm}^{2}$, resulting in a $20-30 \%$ confluence. TUNEL analysis showed that apoptotic cell death in the culture was $<3 \%$ (Fig. 3-1 $B$, $C$, available at https:// doi.org/10.1523/JNEUROSCI.1005-17.2017.f3-1).

\section{Alpha-synuclein exposure}

Astrocyte cultures were exposed to $0.5 \mu \mathrm{M} \alpha$-SYN oligomers or $\alpha$-SYN monomers for $24 \mathrm{~h}$. This concentration was chosen based on our previous investigations of neuronal-glial cocultures, demonstrating that astrocytes rapidly internalized particularly large amounts of $\alpha$-SYN oligomers (Lindström et al., 2017). After exposure, the cells were thoroughly washed in medium two times and continuously cultured in medium without oligomers or monomers. At 0,3 , and $6 \mathrm{~d}$ after exposure, the cells were fixed for further analyses. Parallel control cultures were left untreated and fixed at the same time points.

\section{Time-lapse microscopy}

Cells were recorded using time-lapse microscopy (Nikon Biostation IM Cell Recorder). Images were taken at $20 \times, 40 \times$, or $80 \times$ magnifications every 5 or $10 \mathrm{~min}$. The duration of the experiment was $24 \mathrm{~h}$ during the $\alpha$-SYN oligomer exposure or $72 \mathrm{~h}$ after the $24 \mathrm{~h} \alpha$-SYN oligomer exposure (and wash).

\section{Western blot analysis}

At 0,3 , and $6 \mathrm{~d}$ after $\alpha$-SYN oligomer and monomer exposure, cells were lysed in lysis buffer containing $20 \mathrm{~mm}$ Tris, $\mathrm{pH} 7.5,0.5 \%$ Triton X-100, $0.5 \%$ deoxycholic acid, $150 \mathrm{~mm} \mathrm{NaCl}, 10 \mathrm{~mm}$ EDTA, $30 \mathrm{~mm}$ NaPyroP, $500 \mu \mathrm{M}$ sodium orthovanadate, and $1 \times$ protease inhibitor (Thermo Fisher Scientific, 78430) on ice for $30 \mathrm{~min}$ before centrifugation for $30 \mathrm{~min}$ at $4^{\circ} \mathrm{C} 12,000 \times g$. The supernatants were transferred to new tubes and the pellets and lysates were kept in $-70^{\circ} \mathrm{C}$ until analysis. To study autophagic flux, control cells and $\alpha$-SYN oligomer-exposed cells were treated with bafilomycin ( $500 \mathrm{~nm}$, Millipore) at $24 \mathrm{~h}+6 \mathrm{~d}$ for $6 \mathrm{~h}$ before lysis. Protein concentration was measured using the BCA protein assay kit (Thermo Fisher Scientific, 23225) according to the manufacturer's protocol.

A total volume of $40 \mu \mathrm{l}$ of each sample, containing $20 \mu \mathrm{g}$ of protein, $1 \times$ Bolt Sample Reducing agent (Thermo Fisher Scientific), and $1 \times$ NuPAGE LDS sample buffer (Thermo Fisher Scientific), was loaded to a 
4-12\% NuPAGE Bis-Tris gel (Thermo Fisher Scientific). Chameleon kit 700 and 800 prestandard protein ladders (LICOR) were mixed and added to the gel. The gel was run at $200 \mathrm{~V}$ for $30 \mathrm{~min}$ in Bolt MES SDS Running buffer $(1 \times$, Thermo Fisher Scientific). The PVDF membrane was activated in methanol for $5 \mathrm{~min}$ before transfer at $22 \mathrm{~V}$ for $1 \mathrm{~h}$ in MES transfer buffer $(1 \times)$ supplied with $10 \%$ methanol, $0,1 \%$ Bolt antioxidants (Thermo Fisher Scientific) and $0.01 \%$ SDS. For $\alpha$-SYN monomer and oligomer detection, membranes were fixed with $0.4 \%$ PFA for $30 \mathrm{~min}$ and washed with PBS $3 \times 5$ min before blocking in 5\% BSA in TBS for $1 \mathrm{~h}$ at room temperature. The membranes were then incubated with primary antibodies overnight at $4^{\circ} \mathrm{C}$. The primary antibodies used were as follows: LAMP-1 (1:1000, Abcam, ab24170), LC3B (1:500, Novus Biologicals, NB100-2220SS), p62 (1:500, Novus Biologicals, NBP1-48320SS), GAPDH (Novus Biologicals, NB300-221), and FL-140 (1:1000, Santa Cruz Biotechnology). The following day, the membranes were washed in $0,1 \%$ Tween in TBS (TBS-T) $3 \times 10$ min before incubation with HRP-coupled secondary antibody (1:20,000, Pierce) for $1 \mathrm{~h}$ at room temperature. After $3 \times 10$ min washes with TBS-T, the membranes were incubated with the ECL prime Western blotting detection reagents (1:1 mixture of reagent $A$ and $B$, GE Healthcare) and the signal was measured using the ChemiDoc XRS machine (Bio-Rad).

To detect $\alpha$-SYN oligomers in the pellet, samples were resuspended in $1 \%$ SDS and $1 \times$ protease inhibitor in TBS. The samples were boiled in $95^{\circ} \mathrm{C}$ for $5 \mathrm{~min}$ before sonication for $30 \mathrm{~s}$ with $1 \mathrm{~s}$ pulse on/off and an amplitude of $20 \%$. The samples were treated as the other samples before loading to the gel.

\section{Luminescent ATP detection kit}

Cells were grown in 24 -well plates $\left(5,000\right.$ cells $/ \mathrm{cm}^{2}$ cells per well $)$ and exposed to $\alpha$-SYN oligomers as described previously. The total ATP levels were analyzed at $24 \mathrm{~h}+6 \mathrm{~d}$ with the Luciferase-Based Luminescent ATP Detection Assay Kit (Abcam, ab113849) according to the manufacturer's protocol. As a positive control, cells were incubated with a $5 \mu \mathrm{M}$ concentration of the mitochondrial electron transport inhibitor antimycin A (Sigma-Aldrich, A8674) for 21 h before measurement. Luminescence was measured with an Infinite M1000 plate reader (Tecan). The assay was performed in a biological replicate of $n=6$; that is, from 6 different batches of cells. Luminescence values are presented as the relative change compared with untreated control cultures.

\section{Coculture experiments with RFP/GFAP-expressing astrocytes}

Different coculture systems were used to study cell-to-cell transfer of $\alpha$-SYN oligomers and mitochondria. Unlabeled astrocytes and astrocytes expressing tagged-RFP (tRFP) under the $\mathrm{GFAP}_{\mathrm{ABC} \text { ID }}$ promoter (Holmqvist et al., 2015) were used as either acceptor or donor cells. The different combinations are described below.

$\alpha$-SYN transfer to unexposed, tRFP acceptor astrocytes. Unlabeled astrocytes were treated with Atto 488-labeled $\alpha$-SYN oligomers for $24 \mathrm{~h}$ followed by washes. At $24 \mathrm{~h}+2 \mathrm{~d}$, the exposed astrocytes (donor cells) were trypsinized and added to the unexposed tRFP astrocytes (acceptor cells). After $24 \mathrm{~h}$ of coculture, the cells were fixed. Actin polymerization was inhibited by addition of latrunculin B ( $1 \mu \mathrm{M}$, Sigma-Aldrich $) 3 \mathrm{~h}$ after the coculture was started.

Mitochondria transfer from $\alpha$-SYN oligomer-exposed astrocytes to unexposed, tRFP acceptor astrocytes. Unlabeled astrocytes were treated with unlabeled $\alpha$-SYN oligomers for $24 \mathrm{~h}$ followed by washes. At $24 \mathrm{~h}+$ $1 \mathrm{~d}$, the $\alpha$-SYN oligomer-exposed astrocytes were transfected with cellLight mitochondria-GFP (Mitotracker, Thermo Fisher Scientific) at 20 particles per cell (PPC) (donor cells). Unexposed, tRFP astrocytes (acceptor cells) were added to the donor cells at $24 \mathrm{~h}+2 \mathrm{~d}$. After $24 \mathrm{~h}$ of coculture, the cells were fixed. Actin polymerization was inhibited using latrunculin B $(1 \mu \mathrm{M}) 3 \mathrm{~h}$ after the coculture was started.

Mitochondria transfer from unexposed tRFP astrocytes to $\alpha$-SYN oligomer-exposed acceptor astrocytes. Unlabeled astrocytes were treated with unlabeled $\alpha$-SYN oligomers for $24 \mathrm{~h}$ followed by washes. At $24 \mathrm{~h}+$ $1 \mathrm{~d}$ unexposed, tRFP astrocytes were transfected with Miotracker (20 PPC, donor cells). The tRFP astrocytes (donor cells) were added to the $\alpha$-SYN oligomer-exposed astrocytes at $24 \mathrm{~h}+2 \mathrm{~d}$ (acceptor cells), followed by $24 \mathrm{~h}$ of coculture and fixation. Actin polymerization was inhib- ited using latrunculin B $(1 \mu \mathrm{M}) 3 \mathrm{~h}$ after the coculture was started. Mitochondrial transfer was also studied in parallel cocultures in which neither the acceptor cells nor the donor cells were treated with $\alpha$-SYN oligomers.

\section{Immunocytochemistry}

Cells were fixed in 4\% PFA in PBS, washed, and blocked with 5\% normal goat serum (NGS) and $0.1 \%$ Triton in PBS for $30 \mathrm{~min}$ in room temperature. Primary antibodies were diluted in $0.5 \%$ NGS and $0.1 \%$ Triton in $\mathrm{PBS}$ and added to the cells for $2 \mathrm{~h}$ in room temperature. Thereafter, cells were washed $3 \times$ with $\mathrm{PBS}$ before incubation with secondary antibodies and dyes for $45 \mathrm{~min}$ at $37^{\circ} \mathrm{C}$. After additional washes, cells were mounted with Vectashield Hard Set Mounting medium with DAPI or without DAPI (BioNordika) and analyzed using the fluorescence microscope Observer Z1 Zeiss. Confocal images were taken using Zeiss LSM700 and LSM 710 and 3D images were performed using the IMARIS 8.2 program. The following primary antibodies were used: anti-nestin (1:400, Millipore, ABD69), anti-S100B (1:200, Sigma-Aldrich, S2532), anti-vimentin (1:200, Abcam, ab5733), anti-LAMP1 (1:200, Abcam, ab24170), antiTGN46 (1:100, Abcam, ab50595), anti-COXIV (mouse monoclonal, 1:100, Abcam, ab14744), anti-COXIV (rabbit polyclonal, 1:100, Abcam, ab16056), anti-DRP-1 (1:200, Abcam, ab56788), anti-LC3B (1:200, Abcam, ab51520), anti-Golgi complex antibody (1:200, Abcam, ab103439), and anti-calnexin (1:200, Santa Cruz Biotechnology, sc11397). The following secondary antibodies and dyes were used: Alexa Fluor 488 goat anti rabbit/mouse (1:200, Abcam), Alexa Fluor Cy3 goat anti rabbit/ mouse (1:200, Abcam), and Alexa Fluor 488 phalloidin (Sigma-Aldrich). To stain the plasma membrane, fixed cells were washed $3 \times$ with HBSS (Life Technologies) before incubation with wheat germ agglutinin (WGA), Alexa Fluor 350 conjugate (1:200, Life Technologies) for $10 \mathrm{~min}$. Astrocytic apoptosis was measured using terminal (TdT)-mediated dUTP-biotin reaction mixture (TUNEL, Roche Biochemicals) according to the manufacturer's instructions. Mitochondria were labeled with cellLight mitochondria-GFP BacMam 2.0 (Thermo Fisher Scientific) and $\mathrm{LC}_{3} \mathrm{~B}^{+}$vesicles were labeled with the Premo Autophagy Tandem Sensor RFP-GFP-LC3B Kit. As a control to the Autophagy Tandem Sensor RFPGFP-LC3B Kit, $90 \mu \mathrm{m}$ chlouroscin was added to the cells for $8 \mathrm{~h}$ before fixation. The transfection reagents were mixed in the cell medium at 20 $\mathrm{PPC}$ and added to the cells for $24 \mathrm{~h}$ before fixation.

\section{Transmission electron microscopy (TEM)}

Astrocyte cultures were fixed in $2.5 \%$ glutaraldehyde in $0.1 \mathrm{M}$ sodium cacodylate buffer (SCB), pH 7.4. The cell culture dishes were then rinsed in $0.1 \mathrm{~m} \mathrm{SCB}$ for $10 \mathrm{~min}$ and incubated in $1 \% \mathrm{OsO}_{4}$ in $0.1 \mathrm{~m} \mathrm{SCB}$ for $1 \mathrm{~h}$. Dehydration was performed with $70 \%$ ethanol for $30 \mathrm{~min}$, $95 \%$ ethanol for $30 \mathrm{~min}$, and $99.7 \%$ ethanol for $1 \mathrm{~h}$. The dishes were rinsed with plastic (Agar 100 resin kit, Agar Scientific) and a new, thin layer of plastic was added to the cells for 2-4 h to permit evaporation of the alcohol. A second plastic layer was poured on and left overnight before a thicker, newly made plastic layer was added. The dishes were incubated at room temperature for $1 \mathrm{~h}$ before polymerization in the oven $\left(60^{\circ} \mathrm{C}\right)$ for $48 \mathrm{~h}$. The cells were studied in a Hitachi H-7100 TEM.

\section{Quantifications and statistics}

Intensity measurements of $\alpha$-SYN deposits. In total, 12 images per experiment and time point were captured at days 0,3 , and 6 after $\alpha$-SYN oligomer exposure. Zen 2012 software was used to analyze the intensity and number of $\alpha$-SYN inclusions from four independent experiments. The data were analyzed in GraphPad Prism 6.0 software using KruskalWallis statistical analysis.

Analysis of TUNEL assay. In total, 12 images per experiment and time point were captured at days 0,3 , and 6 after $\alpha$-SYN oligomer exposure or latrunculin B treatment and in parallel control cultures. Two independent experiments were performed and the number of TUNEL ${ }^{+}$cells and the total cell number were determined manually. The data were analyzed in GraphPad Prism 6.0 using two-way ANOVA statistical analysis.

Intensity measurement of Western blot analysis. The LC3BII/I ratio, normalized to GAPDH, and the p62 levels, normalized to GAPDH, were measured in three independent experiments using Image Lab software. 
The data were analyzed in GraphPad Prism 6.0 using one-way ANOVA statistical analysis.

Analysis of autophagic flux using LC3B tandem. To determine whether the autolysosomes were affected by the $\alpha$-SYN treatment, astrocytes were transfected with LC3B tandem where the LC3B protein is coupled to RFP and pH-sensitive GFP. When the autophagosomes fuse with the lysosomes, the $\mathrm{pH}$-sensitive GFP will be degraded. Twenty cells from each time point were analyzed. Cells with only $\mathrm{RFP}^{+} / \mathrm{GFP}^{+}$vesicles and cells with a mixture of $\mathrm{RFP}^{+}$and $\mathrm{RFP}^{+} / \mathrm{GFP}^{+}$vesicles were counted manually in four independent experiments and analyzed using one-way ANOVA statistical analysis.

Morphology analysis of endoplasmic reticulum (ER) in TEM images. Images were captured in close proximity to the nucleus with a magnification of $20,500 \times$ and the ER width was measured using ImageJ software. In total, the ER width from $14 \alpha$-SYN oligomer-exposed astrocytes and 13 untreated, control astrocytes were measured. The data were analyzed in GraphPad Prism 6.0 using Student's $t$ test statistical analysis.

Morphology analysis of mitochondria in TEM images. For measurements of the effect of $\alpha$-SYN oligomers on mitochondrial fusion/fission, the mitochondria were divided into two groups depending on their length: normal mitochondria $(>1 \mu \mathrm{m})$ and dense/fragmented mitochondria $(<1 \mu \mathrm{m})$. Mitochondria within the two groups were quantified in $14 \alpha$-SYN oligomer-exposed astrocytes and in 12 untreated, control astrocytes. The data were analyzed in GraphPad Prism 6.0 using two-way ANOVA statistical analysis.

Morphology analysis of mitochondria in immunocytochemistry images. $\mathrm{COXIV}^{+}$mitochondrial clumps were measured using ImageJ software in 20 images per experiment and time point at days 0,3 , and 6 after $\alpha$-SYN-Cy3 exposure and in parallel control cultures. Three independent experiments were performed and the data were analyzed in GraphPad Prism 6.0 using Kruskal-Wallis statistical analysis.

Quantification of TNTs. For analysis, TNTs were stained with phalloidin and WGA. The inclusion criterion for TNTs herein was protrusions connecting two cells with a length of 5-100 $\mu \mathrm{m}$. In total, 20 images per experiment and time point were captured at day 0,3 , and 6 cultures after $\alpha$-SYN oligomer exposure and in parallel control cultures. Four independent experiments were performed and the number of TNTs was determined manually and analyzed using ANOVA statistical analysis. Actin polymerization was inhibited by the addition of latrunculin B $2 \mathrm{~d}$ after the $24 \mathrm{~h} \alpha$-SYN oligomer exposure. The cell cultures were fixed $1 \mathrm{~d}$ later (at day 3 after the $\alpha$-SYN oligomer exposure). The effect of latrunculin B on TNT formation was analyzed in 20 images per experiment in $\alpha$-SYN oligomer-exposed astrocytes in the absence and presence of latrunculin B. Four independent experiments were performed and the data were analyzed using Student's $t$ test.

Quantifications of transfer in the cocultures. Mitochondria and $\alpha$-SYN ${ }^{+}$acceptor cells in the absence and presence of latrunculin B were counted in 16 images per experiment. Three independent experiments were performed and the data were analyzed using Mann-Whitney statistical analysis.

\section{Results}

\section{$\alpha$-SYN oligomers accumulate in astrocytes after ingestion}

Human ESC-derived astrocytes (Holmqvist et al., 2015) expressing the markers nestin, vimentin, S100 $\beta$, and GFAP (Fig. 1-1 $A$, available at https://doi.org/10.1523/JNEUROSCI.0983-17. 2017.f1-1) were exposed to, $0.5 \mu \mathrm{M}$ Cy3-labeled $\alpha$-SYN oligomers (Fig. 1-1 B, available at https://doi.org/10.1523/JNEUROSCI. 0983-17.2017.f1-1) for $24 \mathrm{~h}$ (see schematic outline in Fig. 1A). Compared with $\mathrm{S} 100 \beta$ and nestin, the expression of GFAP was rather low, but none of the astrocytes were completely GFAP ${ }^{-}$. Live-cell imaging starting instantly after exposure visualized uptake of $\alpha$-SYN oligomers (starred in the figures) in the astrocytes (Fig. 1-2A, available at https://doi.org/10.1523/JNEUROSCI. 0983-17.2017.f1-2). After engulfment (Fig. 1-2A, available at https://doi.org/10.1523/JNEUROSCI.0983-17.2017.f1-2, 11 h 25 $\mathrm{min}$ to $11 \mathrm{~h} 55 \mathrm{~min}$ ), the astrocytes contracted and temporar- ily rounded up as $\alpha$-SYN was transported to the region around the nuclei (Fig. 1-2A, available at https://doi.org/10. 1523/JNEUROSCI.0983-17.2017.f1-2, 19 h 05 min to $21 \mathrm{~h} 36$ $\mathrm{min})$, where it persisted throughout the time-lapse experiment. Contraction after engulfment of large pathogens have been described previously in other phagocytic cells (Evans et al., 1993). Moreover, we confirmed the intracellular location of the engulfed $\alpha$-SYN-Cy3 oligomers in the astrocytes by actin labeling and confocal 3D imaging (Fig. 1B). To investigate whether the $\alpha$-SYN inclusions were degraded by the human astrocytes, the cells were thoroughly washed after the $24 \mathrm{~h} \alpha$-SYN-Cy3 oligomer exposure and cultured for an additional 3 or $6 \mathrm{~d}$ in $\alpha$-SYN-free medium before fixation (see schematic outline in Fig. $1 A$ ). Interestingly, we found that the ingested $\alpha$-SYN oligomers remained in the cells throughout the experiment (Fig. 1-2 B, available at https://doi. org/10.1523/JNEUROSCI.0983-17.2017.f1-2). To verify this result, we performed Western blot analysis of total whole-cell lysates and pellet fractions with antibodies directed to $\alpha$-SYN (Fig. 1-2C, available at https://doi.org/10.1523/JNEUROSCI. 0983-17. 2017.f1-2). The reason that we included analysis of the pellet fractions was that we have noted previously that intracellular deposits of amyloid- $\beta$ in astrocytes end up in the pellet fraction due to their compact and large structure (Söllvander et al., 2016). As expected, SDS treatment of the $\alpha$-SYN oligomers resulted in dissociation into a wide range of high- and low-molecular-weight $\alpha$-SYN species (Fig. 1-2C, available at https://doi. org/10.1523/JNEUROSCI.0983-17.2017.f1-2; Näsström et al., 2011). Interestingly, our data show that there was a reduction in high-molecular-weight $\alpha \mathrm{SYN}$ species in the lysates over time, but the high-molecular-weight $\alpha \mathrm{SYN}$ species in the pellet fraction remained rather intact at all three time points, demonstrating that the $\alpha$-SYN oligomers were not effectively degraded by the cells over the $6 \mathrm{~d}$ time period (Fig. 1-2C, available at https://doi. org/10.1523/JNEUROSCI.0983-17.2017.f1-2). The immunostainings showed that all astrocytes in the $\alpha$-SYN-exposed cultures had $\alpha$-SYN deposits and we did not observe any obvious difference in uptake or accumulation of $\alpha$-SYN in cells with high versus low GFAP expression. In contrast to the oligomers, monomeric $\alpha$-SYN was degraded rapidly by the human astrocytes (Fig. 1-3, $A, B$, available at https://doi.org/10.1523/JNEUROSCI.0983-17. 2017.f1-3).

Quantifications of the Cy3 signal at the different time points after oligomer exposure (Fig. 1C) demonstrated that the total area of the inclusions per astrocyte (Fig. 1D) and the number of deposits per astrocyte (Fig. $1 E$ ) were stable over time and did not change significantly from days 0 to 6 , indicating minimal degradation of the ingested aggregated $\alpha$-SYN during the $6 \mathrm{~d}$ time period. However, the mean area per inclusion (Fig. $1 F$ ) and the mean intensity per field (Fig. $1 G$ ) increased significantly over time $(p<0.001)$. These results could be explained by the fact that the aggregates were brought closer together over the $6 \mathrm{~d}$ period when the $\alpha$-SYN was relocated to the region around the cell nuclei. This is a phenomenon the we demonstrated previously after astrocytic engulfment of amyloid- $\beta$ oligomers (Söllvander et al., 2016).

\section{Lysosomal machinery fails to degrade ingested $\alpha$-SYN oligomers}

To determine whether the internalized $\alpha$-SYN oligomers entered the lysosomal pathway, we performed immunostaining with endosomal/lysosomal-associated membrane protein 1 (LAMP-1). The stainings showed an increased perinuclear localization of LAMP-1 at day 3 after exposure to $\alpha$-SYN oligomers compared 


\section{A}

Cy3 a-SYN oligomers

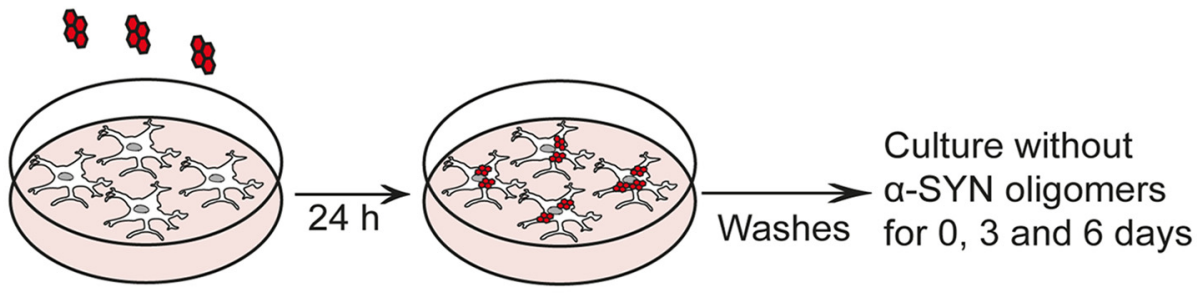

B

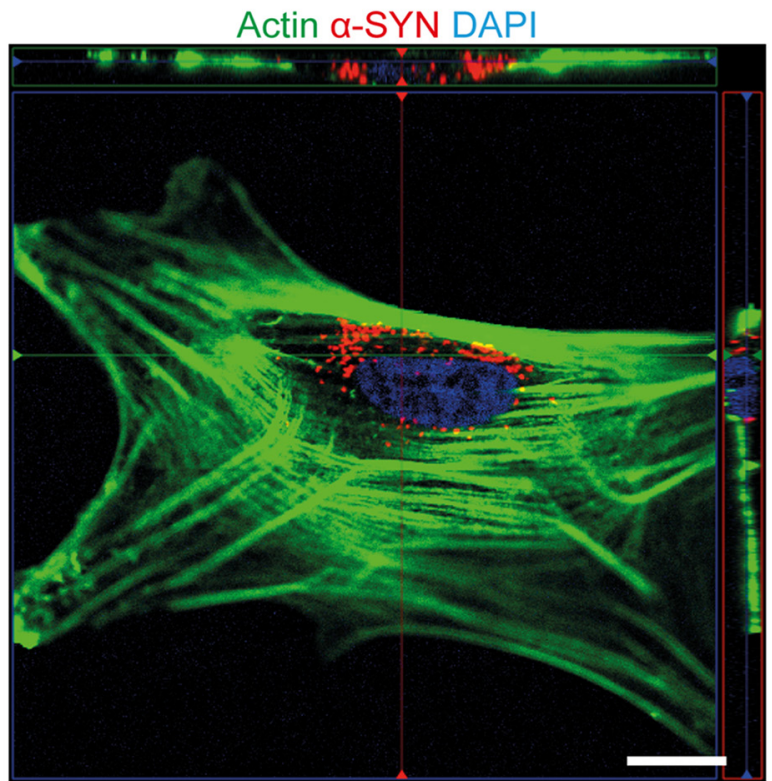

C
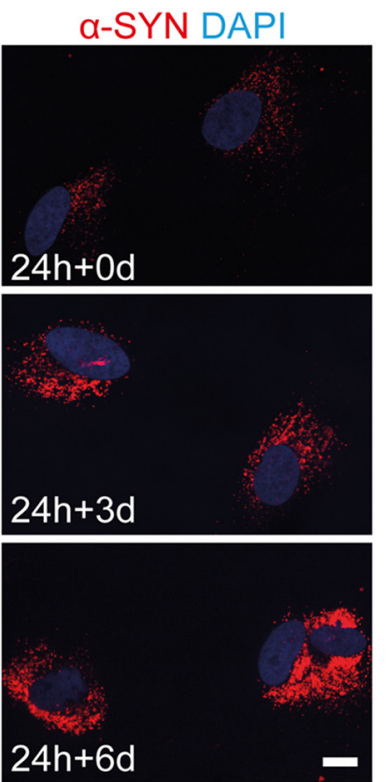

D

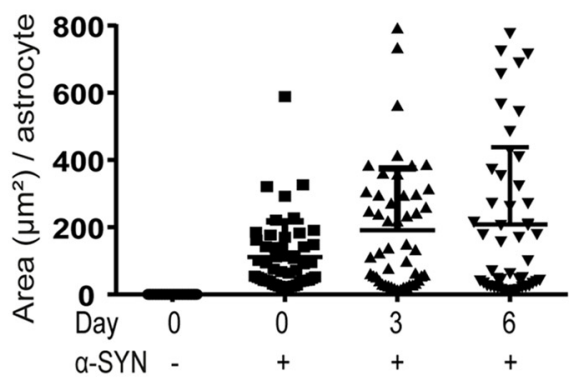

F

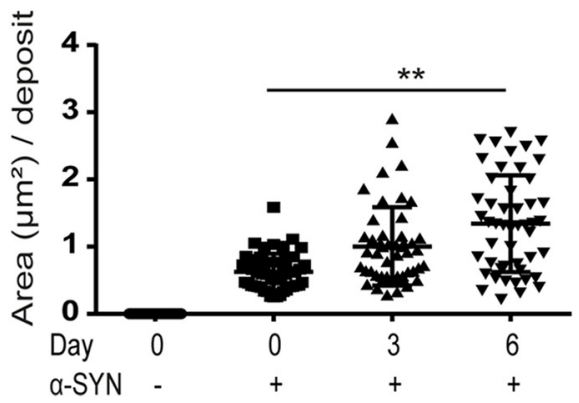

E

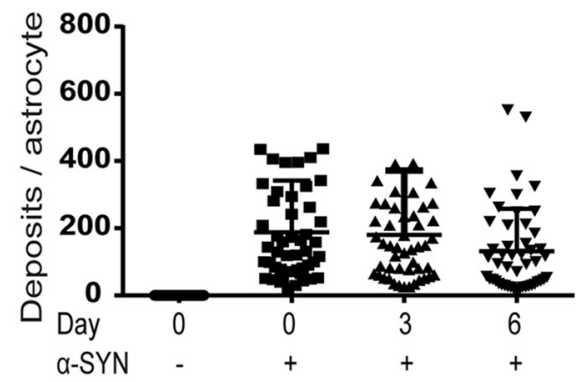

$G$

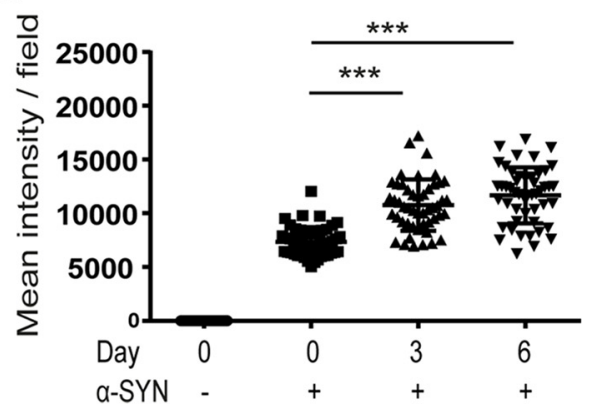

Figure 1. Intracellular $\alpha$-SYN is stored rather than degraded. Human ESC-derived astrocytes (see Fig. 1-1 A, available at https://doi.org/10.1523/JNEUROSCI.0983-17.2017.f1-1) were exposed to 0.5 $\mu \mathrm{m}$ Cy3-labeled $\alpha$-SYN oligomers (see Fig. 1-1 B, available at https://doi.org/10.1523/JNEUROSCI.0983-17.2017.f1-1) for 24h, washed thoroughly, and cultured for an additional 0, 3, or $6 \mathrm{~d}$ in $\alpha$-SYN-free medium before fixation (A). The intracellular location of the $\alpha$-SYN-Cy3 after ingestion (see Fig. 1-2A, available at https://doi.org/10.1523/JNEUROSCI.0983-17.2017.f1-2) was confirmed with confocal imaging (B). Quantification of the $\alpha$-SYN-Cy3 signal at days 0, 3, and 6 (C and Fig. 1-2B, available at https://doi.org/10.1523/JNEUROSCI.0983-17.2017.f1-2) reveled the total area of the $\alpha$-SYN deposits per astrocyte in square millimeters $(\boldsymbol{D})$, the number of $\alpha$-SYN deposits per astrocyte $(\boldsymbol{E})$, the mean area of the deposits in square millimeters $(\boldsymbol{F})$, and the mean intensity of the intracellular $\alpha$-SYN-Cy3 per field $(\boldsymbol{G})$. Western blot analysis confirmed the presence of high-molecular-weight $\alpha$-SYN species in the astrocytes at all three time points (Fig. 1-2C, available athttps://doi.org/10.1523/JNEUROSCI.0983-17.2017.f1-2), demonstrating that only minimal degradation of the ingested oligomeric $\alpha$-SYN occurred, whereas the monomeric $\alpha$-SYN was completely degraded during the $6 \mathrm{~d}$ time period (see Fig. 1-3A, $B$, available at https://doi.org/ 10.1523/JNEUROSCI.0983-17.2017.f1-3).Scalebars: $\boldsymbol{B}, 10 \mu \mathrm{m} ; \boldsymbol{C}, 20 \mu \mathrm{m}$. Data are presented as mean \pm SD from four independent experiments and thelevels of significance were set to ${ }^{*} p<0.05,{ }^{* *} p<0.01$, and $^{* * *} p<0.001(\boldsymbol{E}-\mathbf{G})$. 
A
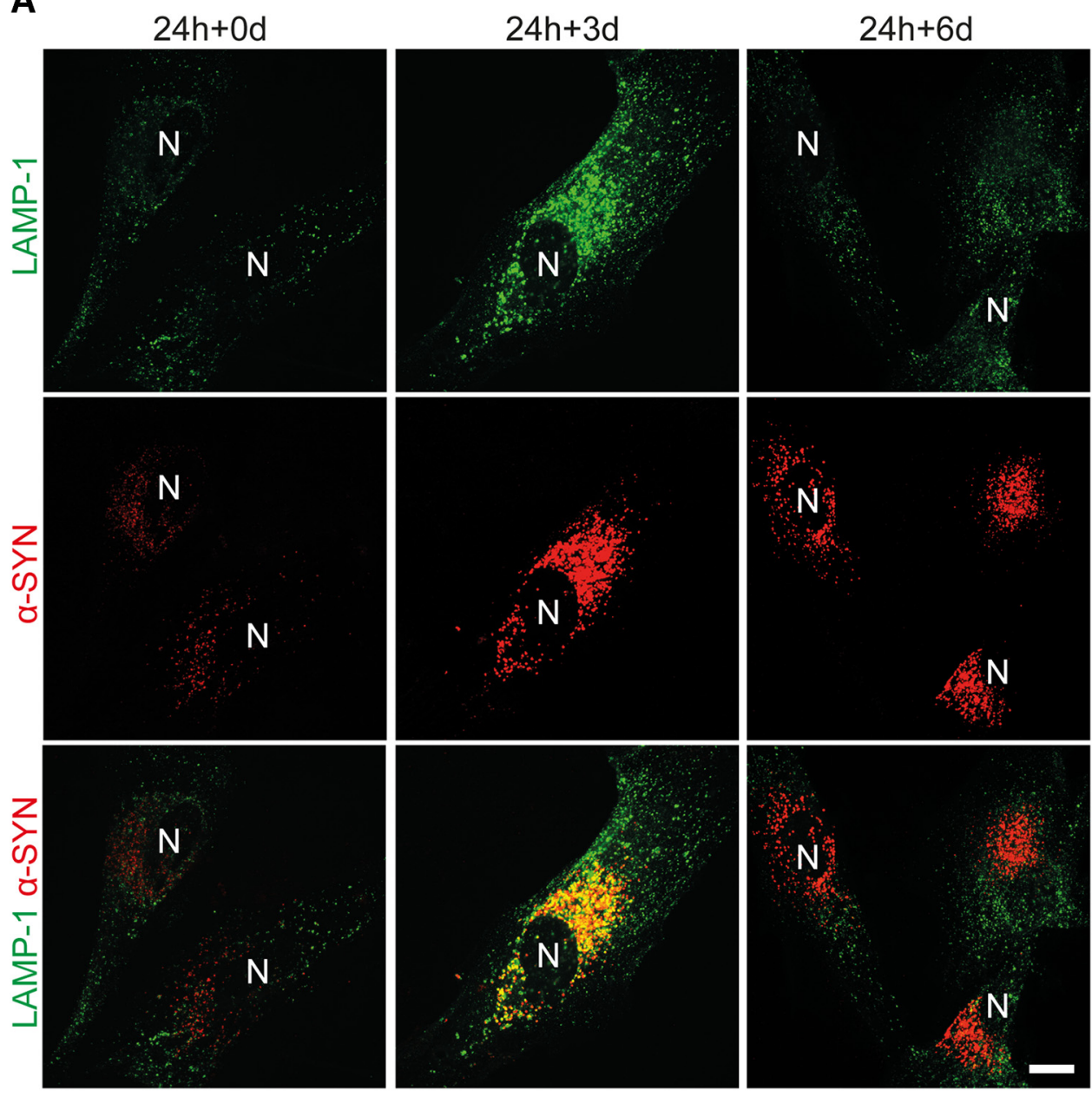

B

C
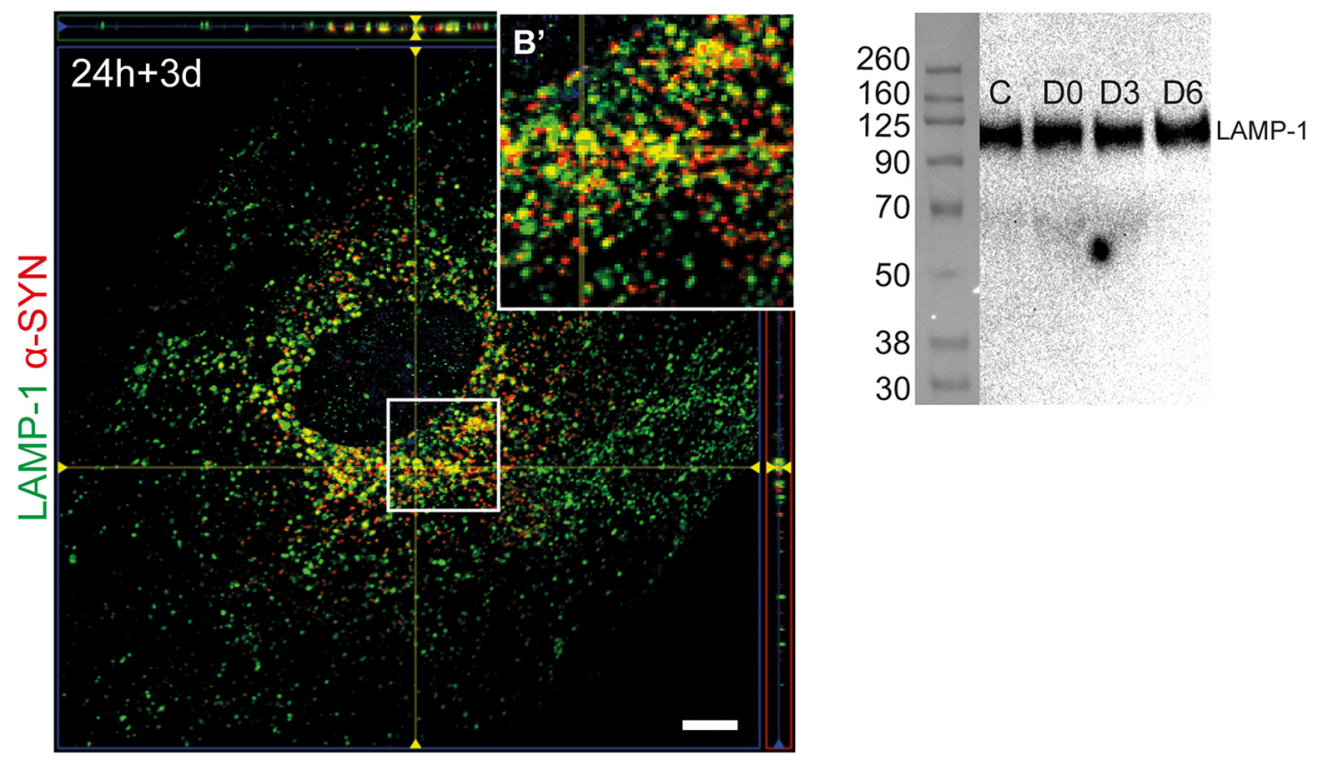

Figure 2. Ingested $\alpha$-SYN only temporarily colocalizes with the lysosomal protein LAMP-1. Representative images of LAMP-1 staining from $\alpha$-SYN oligomer-exposed astrocytes and control cells showed a pronounced colocalization of LAMP-1 and $\alpha$-SYN at day $3(24 \mathrm{~h}+3 \mathrm{~d})$. At day $6(24 \mathrm{~h}+6 \mathrm{~d})$, the colocalization was lost, although the $\alpha$-SYN deposits were not degraded $(\boldsymbol{A}$, Fig. $2-1$, available at https://doi.org/10.1523/JNEUROSCI.0983-17.2017.f2-1, and Fig. 2-2, available at https://doi.org/10.1523/JNEUROSCI.0983-17.2017.f2-2). N, Nucleus. Confocal imaging demonstrated clear colocalization of LAMP-1 and $\alpha$-SYN at day $3(24 \mathrm{~h}+3 \mathrm{~d})(\boldsymbol{B})$. A close-up of the white rectangle is shown in $\boldsymbol{B}^{\prime}$. Western blot analysis revealed no differences in LAMP-1 protein expression between the control and the $\alpha$-SYN oligomer-exposed astrocytes (C). Scale bars: $\boldsymbol{A}, 20 \mu \mathrm{m} ; \boldsymbol{B}, 10 \mu \mathrm{m}$. 
A
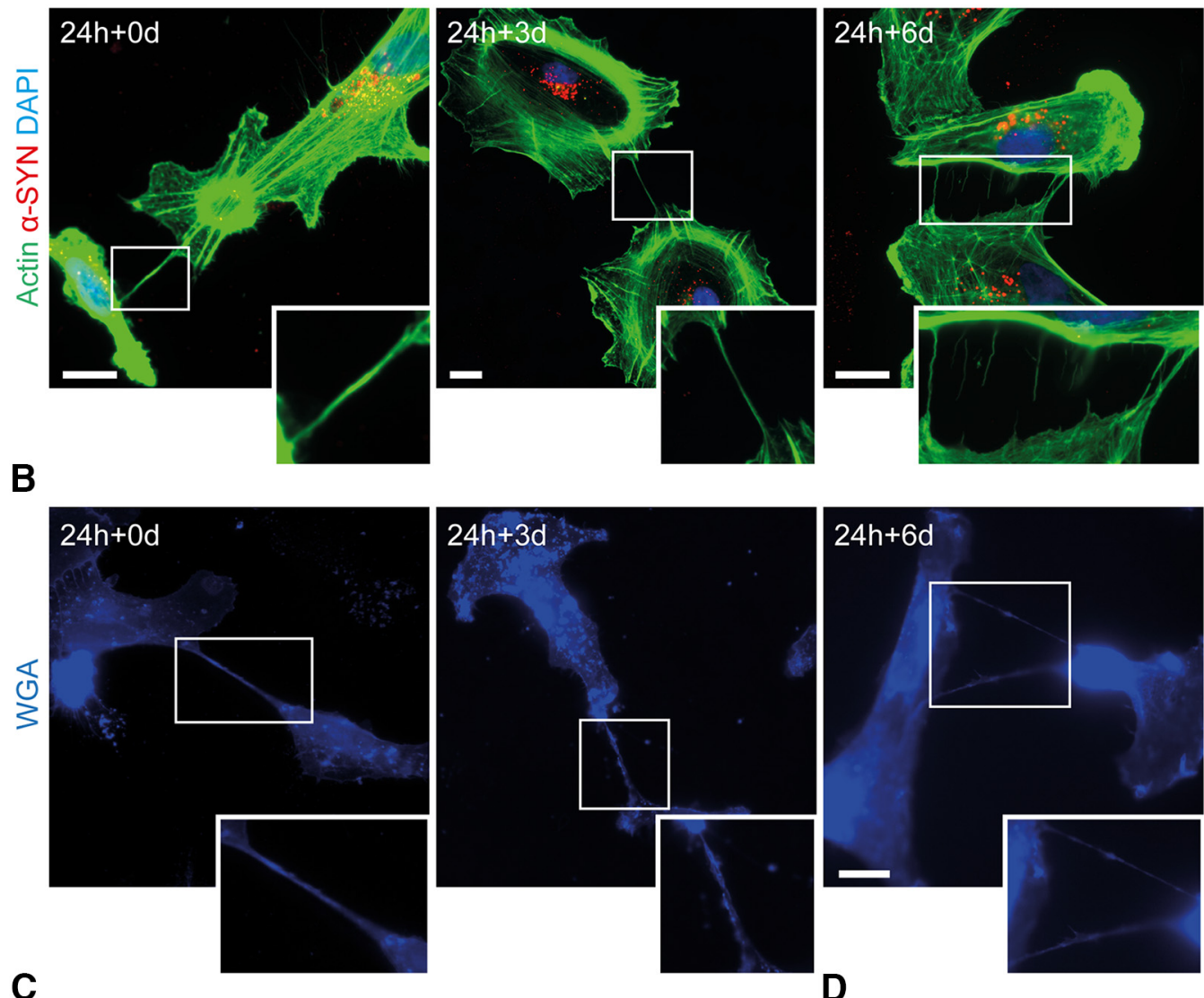

C
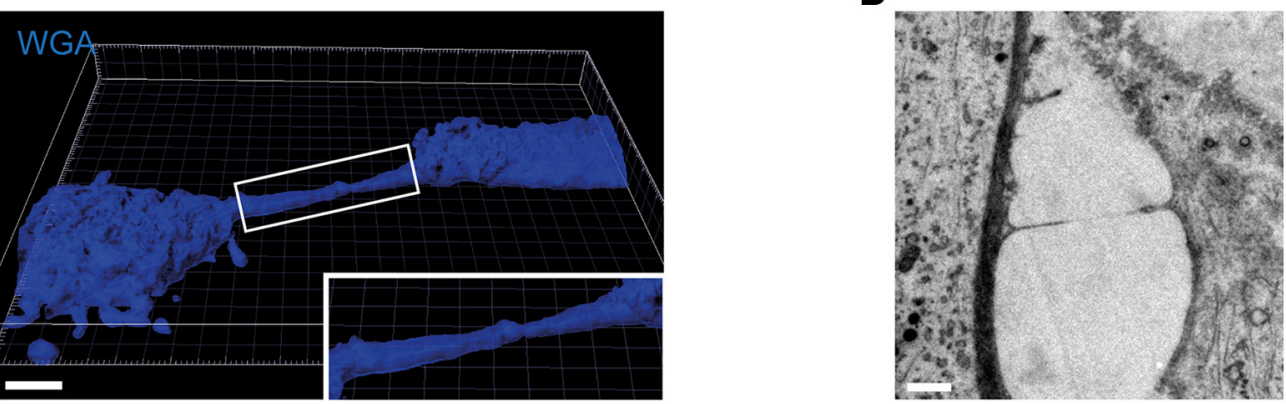

E
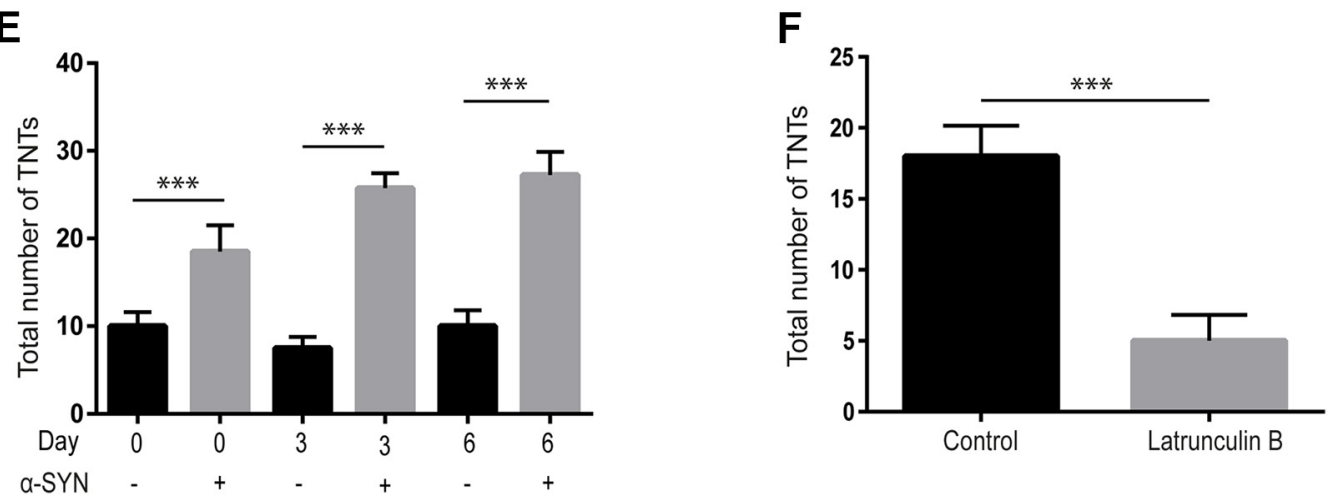

Figure 3. Accumulation of $\alpha$-SYN oligomers induces TNT formation. F-actin labeling using phalloidin $(\boldsymbol{A})$ and membrane staining using WGA (B) showed that TNTs were formed between the astrocytes at 0, 3, and $6 \mathrm{~d}(24 \mathrm{~h}+0 \mathrm{~d}, 24 \mathrm{~h}+3 \mathrm{~d}$, and $24 \mathrm{~h}+6 \mathrm{~d}$ ) after $\alpha$-SYN oligomer exposure. Confocal 3D imaging (Cand Fig. 3-1 A, available at https://doi.org/10.1523/JNEUROSCI.0983-17. 2017.f3-1) and TEM analysis (D) confirmed the presence of TNTs. Quantification of the total number of TNTs in cultures treated with $\alpha$-SYN oligomers or in parallel control cultures showed that the number of TNTs was increased significantly after $\alpha$-SYN oligomer exposure at all time points. Moreover, the number of TNTs increased over time in the $\alpha$-SYN oligomer-treated cultures (E). Latruculin B treatment reduced the number of TNTs significantly $(\boldsymbol{F})$. Importantly, neither the high load of $\alpha$-SYN oligomers nor the treatment with latrunculin B at the concentration and exposure time used induced any obvious toxicity or cell death, as indicated by TUNEL staining and the total cell number (Fig. 3-1 B, C, available at https://doi.org/10.1523/JNEUROSCI.0983-17.2017.f3-1). Scale bars: $\boldsymbol{A}, \boldsymbol{B}, 20 \mu \mathrm{m} ; \boldsymbol{C}, 5 \mu \mathrm{m} ; \boldsymbol{D}, 1 \mu \mathrm{m}$. Data are presented as mean \pm SD from four independent experiments and the levels of significance were set to ${ }^{*} p<0.05$, ${ }^{* *} p<0.01$, and ${ }^{* * *} p<$ $0.001(\boldsymbol{E}, \boldsymbol{F})$. 
A

B
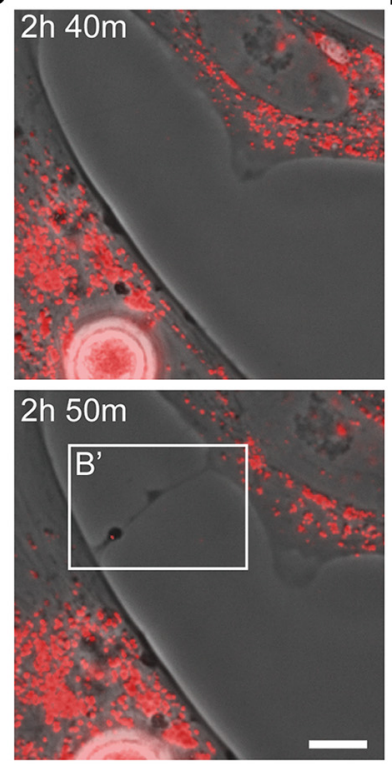

D

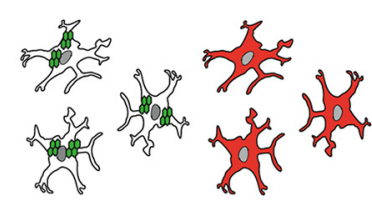

Atto-488 a-SYN exposed donor cells

GFAP *tRFP acceptor cells
A'
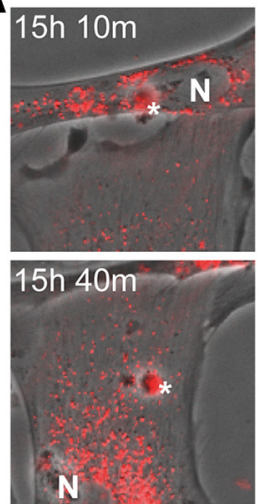

B'
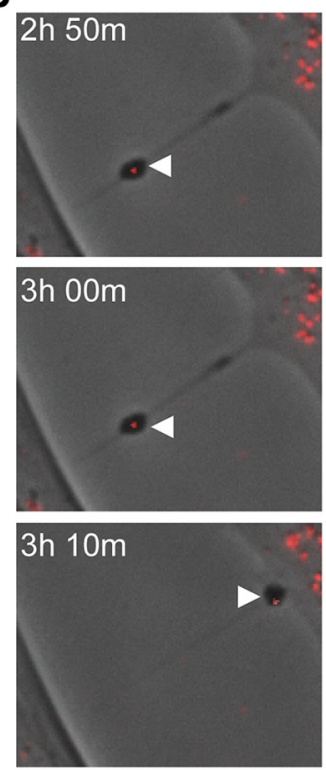

E

C
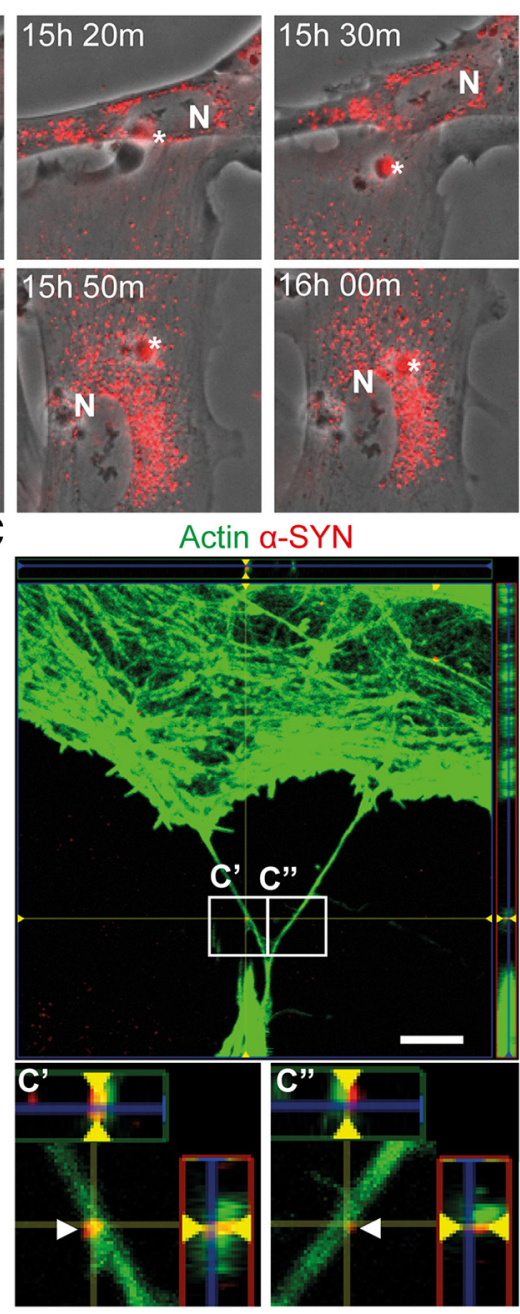

E'
F

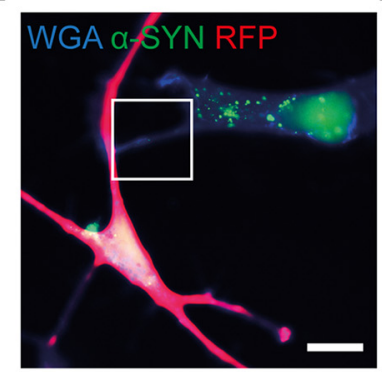

F'

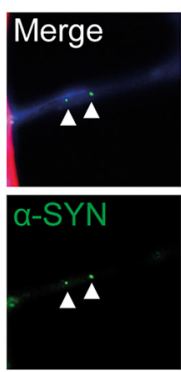

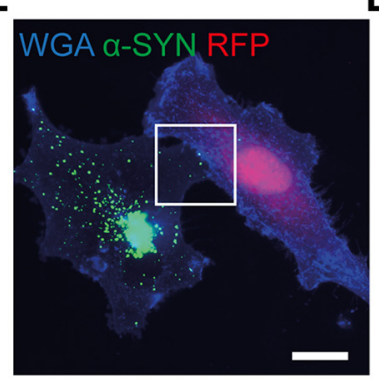

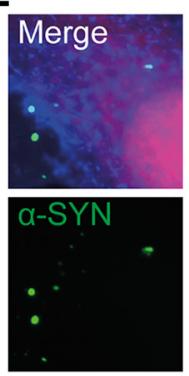

G

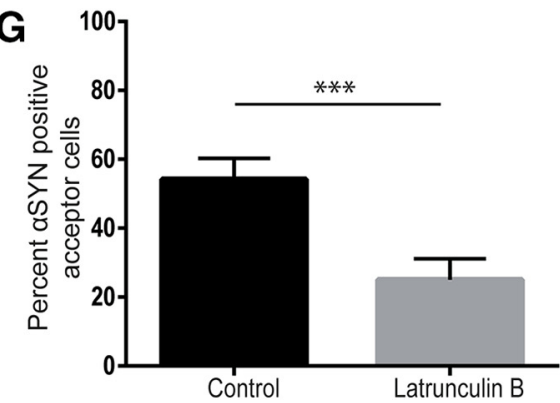

Figure 4. TNTs contribute to $\alpha$-SYN transmission. Time-lapse experiments of $\alpha$-SYN-Cy3 oligomer-exposed cultures showed that $\alpha$-SYN was transported between the astrocytes in the culture via direct contact or via TNTs (see Fig. 4-1A, available at https://doi.org/10.1523/JNEUROSCI.0983-17.2017.f4-1). The different time points after $\alpha$-SYN oligomer exposure are indicated. Direct transmission by membrane fusion of two astrocytes is shown in $\boldsymbol{A}$. Close-ups of the cell-to-cell contact region (white rectangle) demonstrate transmission of an $\alpha$-SYN aggregate (white star) from the top cell to the bottom cell ( $15 \mathrm{~h} 20 \mathrm{~min}$ to $15 \mathrm{~h} 30 \mathrm{~m}$ after $24 \mathrm{~h}$ of $\alpha$-SYN oligomer exposure) $\left(\boldsymbol{A}^{\prime}\right)$. The $\alpha$-SYN is then relocated toward the cell nuclei (N). Transfer of $\alpha$-SYN-Cy3 via TNTs is shown in B. The TNT formation was rather quick and took $<10 \mathrm{~min}(2 \mathrm{~h} 40 \mathrm{~min}$ to $2 \mathrm{~h} 50 \mathrm{~min})$ (B). Close-up imaging (white rectangle) over the after 20 min demonstrated clear TNT-mediated transfer of aggregated $\alpha$-SYN (white arrowheads) ( $\left.\boldsymbol{B}^{\prime}\right)$. Confocal microscopy confirmed the presence of $\alpha$-SYN in (Figure legend continues.) 
with untreated control astrocytes (Fig. $2 A$ and Fig. 2-1 $A, B$, available at https://doi.org/10.1523/JNEUROSCI.0983-17.2017.f2-1). Moreover, we confirmed that, at this time point $(24 \mathrm{~h}+3 \mathrm{~d})$, most of the intracellular $\alpha$-SYN deposits colocalized with the LAMP $-{ }^{+}$vesicles (Fig. $\left.2 A, B\right)$. Notably, at day $6(24 \mathrm{~h}+6 \mathrm{~d})$, the colocalization of LAMP-1 and $\alpha$-SYN was reduced dramatically, although the $\alpha$-SYN inclusions had not been degraded (Fig. $2 A$ and Fig. 2-1, available at https://doi.org/10.1523/JNEUROSCI. 0983-17.2017.f2-1). LAMP-1 staining was also less perinuclear at the latest time point without accomplishing the degradation (Fig. 2A and Fig. 2-1A, available at https://doi.org/10.1523/ JNEUROSCI.0983-17.2017.f2-1). Western blot analysis of whole-cell lysates did not show any changes in total LAMP-1 expression between the control and $\alpha$-SYN-exposed astrocytes (Fig. 2C), indicating that the endosomes/lysosomes were only redistributed inside the cells. Next, we investigated whether the engulfed $\alpha$-SYN oligomers came into contact with mature lysosomes. For this purpose, $\alpha$-SYN oligomers were prelabeled with the $\mathrm{pH}$-dependent dye pHrodo before being added to the astrocytes. The pHrodo dye is only initiated to fluoresce at low $\mathrm{pH}$ such as that inside acidic lysosomes. We found pHrodo staining at all the time points studied $(24 \mathrm{~h}+0 \mathrm{~d}, 24 \mathrm{~h}+3 \mathrm{~d}$, and $24 \mathrm{~h}+6 \mathrm{~d})$, indicating that at least some of the ingested oligomers were transported to acidic lysosomes (Fig. 2-2, available at https://doi.org/ 10.1523/JNEUROSCI.0983-17.2017.f2-2). However, the pHrodo signal did not decline over time. Instead, the fraction of intracellular $\alpha$-SYN that was pHrodo labeled accumulated further and formed deposits/inclusions $(24 \mathrm{~h}+6 \mathrm{~d})$ in the perinuclear region, confirming severe failure of the lysosomal degradation. Therefore, the accumulation of pHrodo-labeled $\alpha$-SYN was similar to the accumulation of Cy3-labeled $\alpha$-SYN. These results show that the engulfed oligomeric $\alpha$-SYN was transported to lysosomal compartments, but the astrocytes were incapable of degrading the $\alpha$-SYN oligomers by the lysosomal machinery.

Intracellular accumulation of $\alpha$-SYN induces TNT formation Cell-to-cell contacts via, for example, TNTs could facilitate intercellular spreading of pathogenic proteins and organelles. To investigate whether the high load of intracellular $\alpha$-SYN deposits affected the formation of TNTs between the astrocytes in the culture, we stained the cellular cytoskeleton with the actin-binding dye phalloidin (Fig. 3A) and the plasma membrane with WGA (Fig. $3 B)$. We found that TNTs were frequently formed between the astrocytes at $24 \mathrm{~h}+0 \mathrm{~d}, 24 \mathrm{~h}+3 \mathrm{~d}$, and $24 \mathrm{~h}+6 \mathrm{~d}$ (hereafter referred to as days 0,3 , and 6; Fig. $3 A, B$ ). Analysis with confocal microscopy (Fig. $3 C$ and Fig. 3-1A, available at https:// doi.org/10.1523/JNEUROSCI.0983-17.2017.f3-1) and TEM (Fig. $3 D$ ) further confirmed the presence of TNTs. Quantification of the total number of TNTs in cultures treated with $\alpha$-SYN oligom-

$\leftarrow$

(Figure legend continued.) actin-labeled TNTs ( $\boldsymbol{C}$ and Fig. 4-1B, available at https://doi.org/10. 1523/JNEUROSCI.0983-17.2017.f4-1), close-up of the white rectangles are shown in $C^{\prime}$ and $\boldsymbol{C}^{\prime \prime}$ (white arrowheads indicate $\alpha$-SYN). Cocultures of unlabeled astrocytes exposed to Atto 488labeled $\alpha$-SYN oligomers and untreated GFAP::tRFP astrocytes ( $\boldsymbol{D}$ and Fig. 4-2, available at https://doi.org/10.1523/JNEUROSCI.0983-17.2017.f4-2) demonstrated transfer of $\alpha$-SYN to unaffected astrocytes via direct transfer $(\boldsymbol{E})$ and TNTs $(\boldsymbol{F})$. Close-ups of the cell-to-cell direct contact region and TNTs (white rectangles) are shown in $\boldsymbol{E}^{\prime}$ and $\boldsymbol{F}^{\prime}$, respectively (white arrowheads in $\boldsymbol{F}^{\prime}$ indicate $\alpha$-SYN). Latruculin B treatment reduced the percentage of $\alpha$-SYN ${ }^{+}$acceptor cells significantly (G). Scale bars: $\boldsymbol{A}-\boldsymbol{C}, 10 \mu \mathrm{m} ; \boldsymbol{E}, \boldsymbol{F}, 20 \mu \mathrm{m}$. Data are presented as mean \pm SEM from three independent experiments and the levels of significance were set to ${ }^{*} p<0.05,{ }^{* *} p<0.01$, and ${ }^{* * *} p<0.001$ (G).

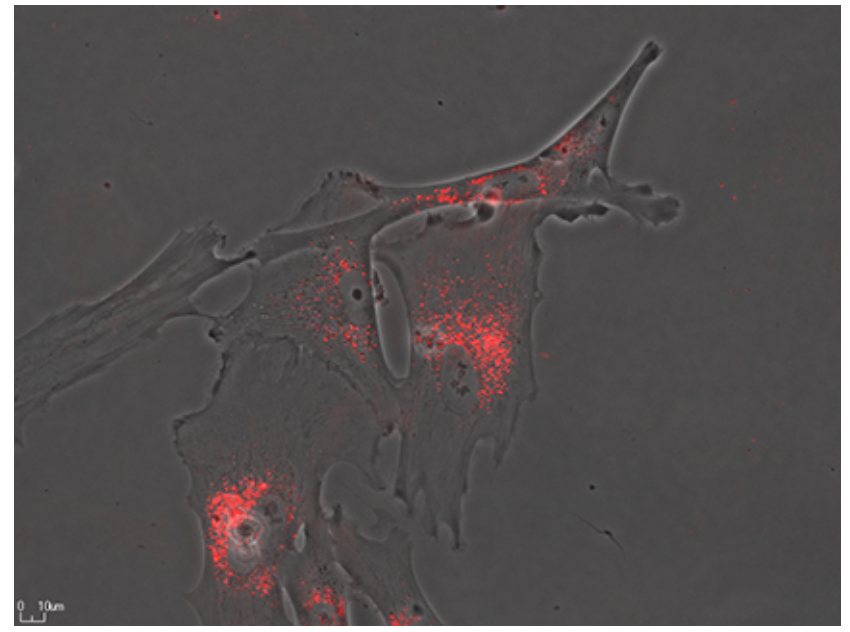

Movie 1. Time-lapse movie demonstrating that $\alpha$-SYN-Cy3 (red, indicated with yellow arrow) are transferred from one astrocyte to another via thin, TNT-like cell protrusions (first transfer) and by close, membrane-to-membrane contact (second transfer).

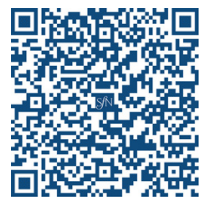

ers and in untreated control cultures showed that the $\alpha$-SYN oligomer exposure clearly induced TNT formation because there were significantly more TNTs in the $\alpha$-SYN oligomer-exposed cultures (Fig. 3E). Moreover, the number of TNTs increased over time (from $0-3 \mathrm{~d}$ and from $0-6 \mathrm{~d}, p<0.001$ ) after the $24 \mathrm{~h}$ of $\alpha$-SYN oligomer exposure. Inhibition of actin polymerization by the addition of latrunculin $B$ reduced the number of TNTs in the astrocyte culture significantly (Fig. $3 F, p<0.001$ ). Importantly, neither the high load of $\alpha$-SYN oligomers nor the treatment with latrunculin $\mathrm{B}$ at the concentration and exposure time used induced any obvious toxicity or cells death, as indicated by TUNEL staining and the total cell number (Fig. 3-1B,C, available at https://doi.org/10.1523/JNEUROSCI.0983-17.2017.f3-1).

\section{TNTs contribute to $\alpha$-SYN transmission}

Time-lapse experiments with Cy3-labeled $\alpha$-SYN oligomerexposed cultures demonstrated that $\alpha$-SYN aggregates of different sizes (up to $5 \mu \mathrm{m}$ in diameter) could transfer between the astrocytes in the culture (Fig. $4 A, B$ and Fig. 4-1 $A$, available at https://doi.org/10.1523/JNEUROSCI.0983-17.2017.f4-1, and Movies 1, 2, and 3). Direct transfer occurred between astrocytes that were in close contact (Fig. $4 A$ and Movie 1, second transfer). Interestingly, we also noticed frequent transfer of $\alpha$-SYN-Cy3 aggregates via thin cell protrusions, which resembled TNTs (Fig. 4-1 A, available at https://doi.org/10.1523/JNEUROSCI.0983-17. 2017.f4-1, and Movie 1, first transfer). Accordingly, time-lapse recordings also revealed transfer of $\alpha$-SYN-Cy3 between the astrocytes via newly formed TNTs (Fig. $4 B$ and Movies 2 and 3). Our time lapse-experiments indicated that very large inclusions of $\alpha$-SYN were transported via direct cell contact, whereas smaller aggregates were easily transported via TNTs. Using confocal microscopy, we confirmed the presence of $\alpha$-SYN-Cy3 within actin-labeled TNTs (Fig. $4 C$ and Fig. 4-1B, available at https://doi.org/10.1523/JNEUROSCI.0983-17.2017. f4-1). Moreover, cocultures of unlabeled astrocytes exposed to $\alpha$-SYN oligomers and untreated astrocytes expressing tRFP under the GFAP $\mathrm{ABC1D}_{\mathrm{D}}$ promotor (Holmqvist et al., 2015; Fig. 4D and Fig. 4-2, available at https://doi.org/10.1523/JNEUROSCI. 0983-17.2017.f4-2) verified that $\alpha$-SYN-containing astrocytes 


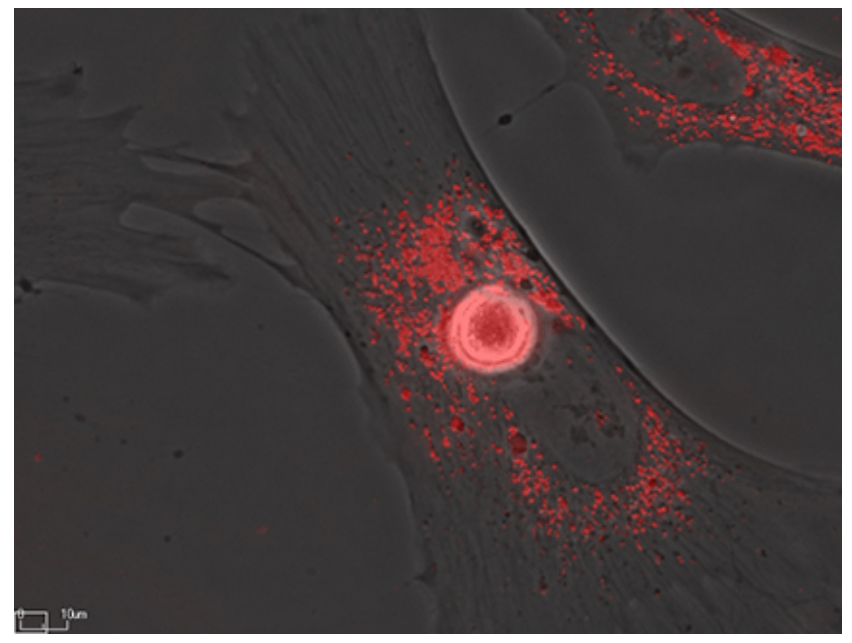

Movie 2. Time-lapse movie demonstrating the formation of TNTs between two astrocytes (indicated with yellow arrow).

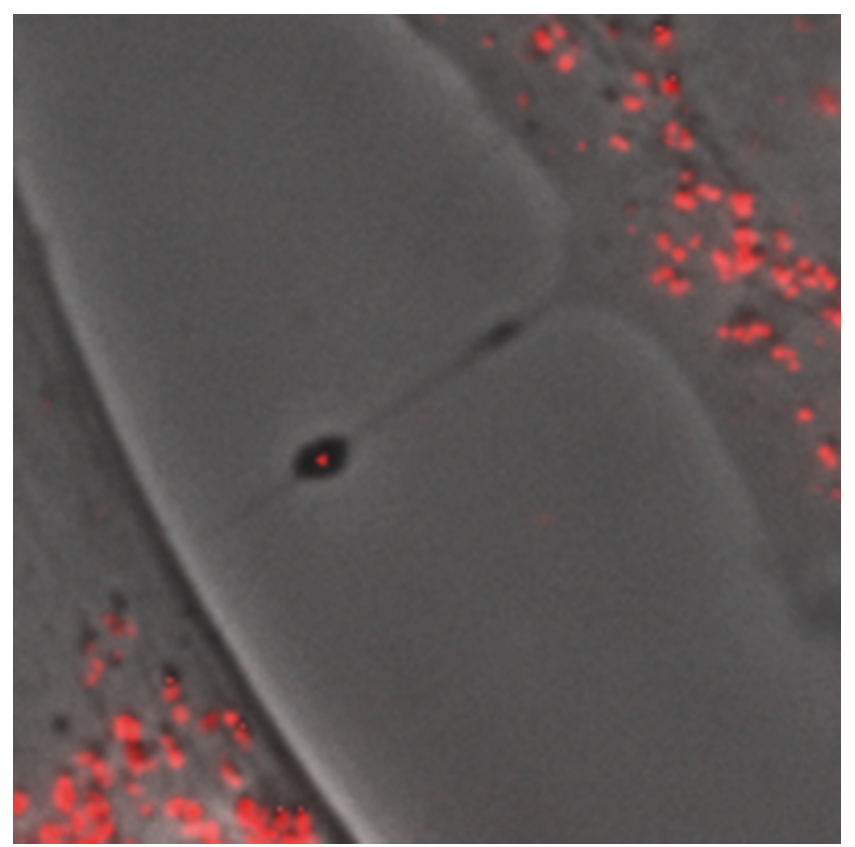

Movie 3. Close-up of Movie 2 demonstrating transfer of $\alpha$-SYN-Cy3 (red, indicated with yellow arrow) from one astrocyte to another via the newly formed TNT.

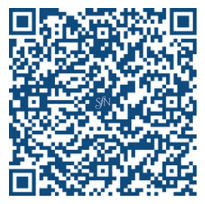

transferred $\alpha$-SYN to unaffected astrocytes via direct cell contact (Fig. 4E) and via TNTs (Fig. 4F). The $\alpha$-SYN TNT-mediated transmission was reduced significantly after pharmacological inhibition of actin polymerization using latrunculin B (Fig. $4 G, p<$ 0.001). However, we cannot exclude that other transfer mechanisms are also affected by the latrunculin B treatment. Altogether, these data clearly demonstrate that astrocytic transfer of $\alpha$-SYN occurs via TNTs in vitro and that pharmacological inhibition of actin polymerization prevents $\alpha$-SYN transfer.

\section{Storage of $\alpha$-SYN results in ER swelling and impaired mitochondrial dynamics}

Immunocytochemistry followed by confocal microscopy demonstrated that the $\alpha$-SYN-Cy3 inclusions were situated in the region of the trans-Golgi network (TGN) (Fig. 5A and Fig. 5-1 A, available at https://doi.org/10.1523/JNEUROSCI.0983-17.2017. f5-1), but immunostaining with an anti-Golgi complex antibody indicated that the accumulation did not result in TGN fragmentation (Fig. 5B). However, from TEM analysis, it was obvious that the $\alpha$-SYN accumulation resulted in severe defects in other cellular organelles. Six days after $\alpha$-SYN oligomer exposure, the astrocytes displayed the typical appearance of ER swelling, with a pronounced increased volume of the ER lumen resembling a vesicular appearance (Fig. 5C). Quantification of the ER width in $\alpha$-SYN oligomer-exposed cultures and untreated control cultures revealed that the $\alpha$-SYN treatment increased the ER width significantly $(p<0.001$; Fig. $5 D)$ ). Furthermore, we performed immunostainings using specific antibodies to the ER-marker calnexin. The results from the immunostainings showed that there was a clearly higher expression of calnexin in the perinuclear region of $\alpha$-SYN oligomers exposed astrocytes compared with control astrocytes (Fig. 5E and Fig. 5-1B, available at https://doi.org/10.1523/JNEUROSCI.0983-17.2017.f5-1).

Moreover, $\alpha$-SYN oligomer-exposed cultures displayed altered mitochondrial morphology, with an elevated number of small and dense mitochondria (Fig. 6A). To be able to quantify the effect on mitochondrial fusion/fission, we divided the mitochondria into two groups depending on their length and their dense/fragmented morphologies (the normal mitochondria were $>1 \mu \mathrm{m}$, whereas small/dense mitochondria were $<1 \mu \mathrm{m}$ ). Quantification of the number of mitochondria in the two groups showed that $\alpha$-SYN oligomer exposure increased the percentage of small and dense mitochondria significantly $(p<0.001)$ and decreased the percentage of normal mitochondria $(p<0.001$; Fig. $6 B)$. Immunostaining with the mitochondrial marker COXIV demonstrated pathological clusters of mitochondria in the astrocytes, further verifying the disrupted mitochondrial dynamics (Fig. $6 \mathrm{C}$ and Fig. 6-1 $A$, available at https://doi.org/10.1523/JNEUROSCI. 0983-17.2017.f6-1). Quantification of the total area of the $\mathrm{COXIV}^{+}$regions in astrocytes at day 6 demonstrated that the presence of mitochondrial clusters increased significantly after $\alpha$-SYN oligomer exposure (Fig. 6D). Double staining using specific antibodies to COXIV and DRP-1 followed by confocal imaging revealed an organized pattern of mitochondria and the fission-regulating protein 0 and $3 \mathrm{~d}$ after $\alpha$-SYN oligomer exposure, preceding the excessive amount of fragmented mitochondria at day 6 (Fig. $6 E, E^{\prime}$ and Fig. 6-1 B, available at https://doi. org/10.1523/JNEUROSCI.0983-17.2017.f6-1). These results indicate that the mitochondrial clusters observed in Figure 6, $C$ and $D$, may be due, at least in part, to increased mitochondrial fragmentation. Interestingly, ATP measurement showed only a very slight decrease (7\%) in ATP levels after $\alpha$-SYN oligomer treatment. In control cultures treated with the electron transport inhibitor antimycin A, there was also a very modest decrease in ATP levels (13\%) compared with untreated cultures (Fig. $6 F$ ). These results, together with the low apoptotic frequency after $\alpha$-SYN oligomer exposure observed with the TUNEL assays (Fig. 3-1 B, available at https://doi.org/10.1523/JNEUROSCI.0983-17. 2017. f3-1), indicate that the astrocytes somehow are able to compensate for the substantial mitochondrial damage. 
A

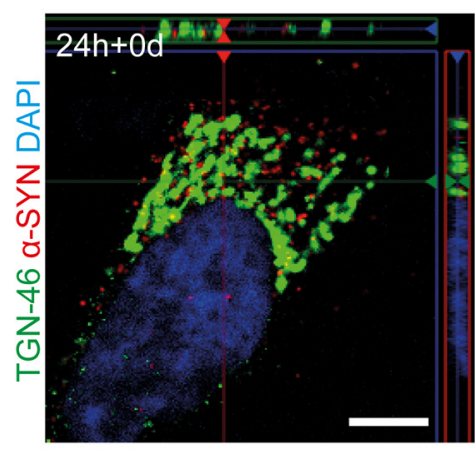

B

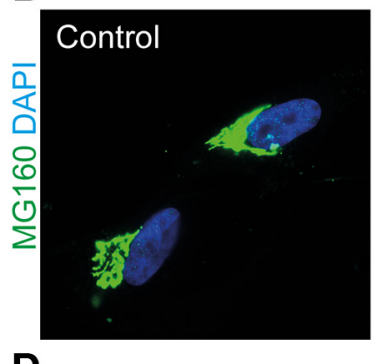

D

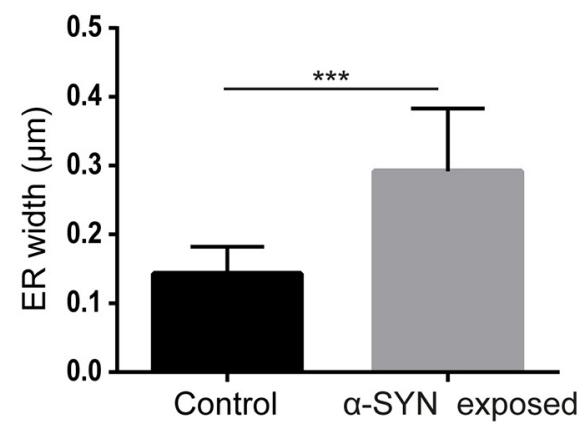

E

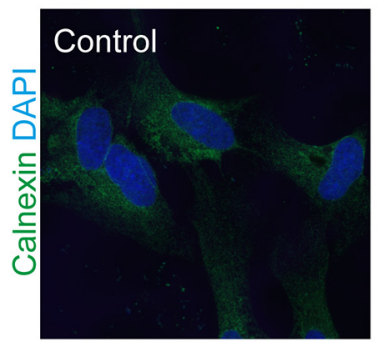

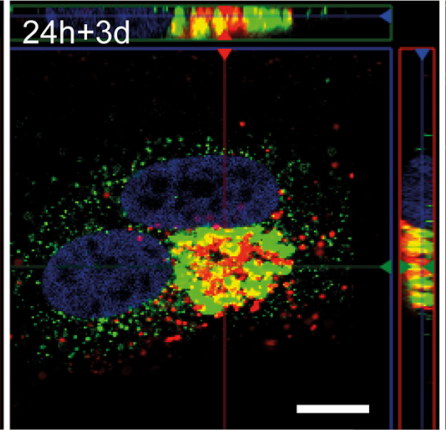

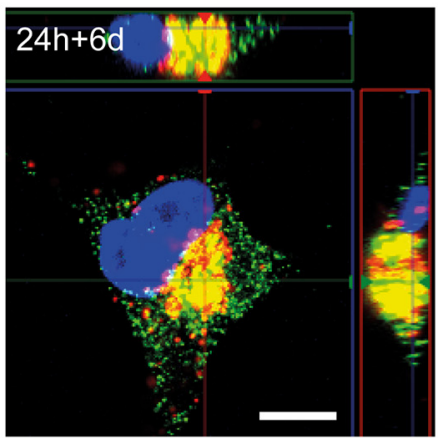

C
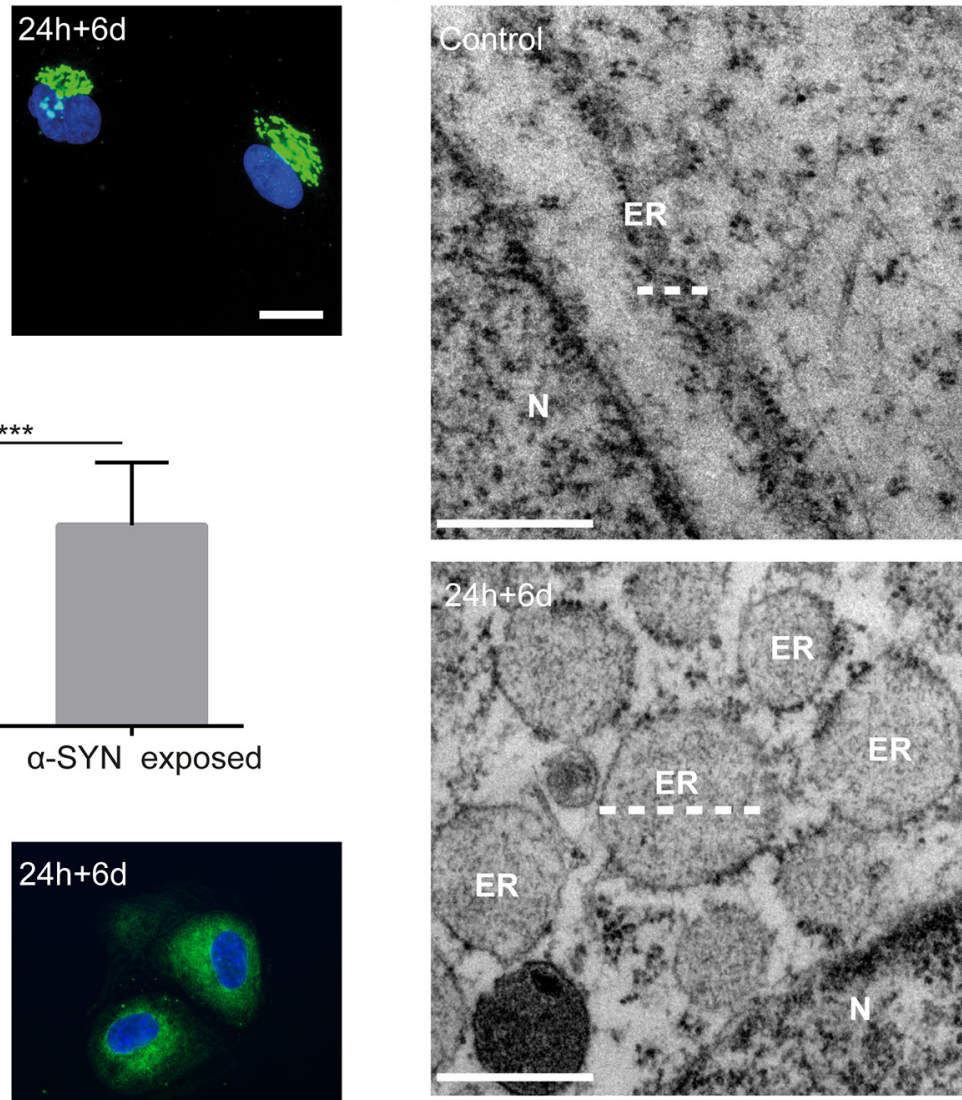

Figure 5. Intracellular storage of $\alpha$-SYN in the TGN region causes ER swelling. Confocal microscopy imaging showed that $\alpha$-SYN-Cy3 inclusions localized to the region of the TGN46 ${ }^{+}$TGN over time ( $\boldsymbol{A}$ and Fig. 5-1A, available at https://doi.org/10.1523/JNEUROSCI.0983-17.2017.f5-1). Immunostainings with specific anti-Golgi complex antibodies demonstrated that the accumulation of ingested $\alpha$-SYN oligomers in the TGN region did not induce Golgi fragmentation (B). TEM analysis of astrocytes $6 \mathrm{~d}$ after $\alpha$-SYN oligomer exposure ( $24 \mathrm{~h}+6 \mathrm{~d}$ ) indicated that the $\alpha$-SYN storage induced ER swelling $(\boldsymbol{C})$ (white dotted lines indicate ER). Quantification of the ER width confirmed the induced ER swelling in oligomer-exposed astrocytes $(\boldsymbol{D})$. Representative images from immunostainings with the anti-calnexin antibody showed a higher expression of calnexin in the perinuclear region of $\alpha$-SYN oligomer-exposed astrocytes compared with control ( $\boldsymbol{E}$ and Fig. 5 - $1 B$, available at https://doi.org/10.1523/JNEUROSCI.0983-17.2017.f5-1). Scale bars: $\boldsymbol{A}, 10 \mu \mathrm{m} ; \boldsymbol{B}, 20 \mu \mathrm{m} ; \boldsymbol{C}, 500 \mathrm{~nm} ; \boldsymbol{E}, 20 \mu \mathrm{m}$. Data are presented as mean \pm SD from 14 $\alpha$-SYN-exposed and 13 control astrocytes and the levels of significance were set to ${ }^{*} p<0.05,{ }^{* *} p<0.01$, and ${ }^{* * *} p<0.001$ (D).

\section{Accumulation of $\alpha$-SYN affects the autophagosomal machinery}

Normally, defected mitochondria and protein aggregates are degraded and removed from the cell by autophagy. When autophagy is induced, the autophagosome is formed by conjugation of cytosolic LC3B I (17 kDa) to phosphotidylethanolamine, forming LC3BII (15 kDa), which is recruited to the autophagosomal membrane by p62 (Katsuragi et al., 2015). The autophagosome then fuses with the lysosome to form the autolysosome in which the low $\mathrm{pH}$ will facilitate degradation of the material. During the fusion with the lysosomes, the low $\mathrm{pH}$ also degrades the LC3BII and p62 proteins. To investigate whether the increased number of fragmented mitochondria after $\alpha$-SYN exposure was due to ineffective mitophagy, we next examined various steps of the autophagy pathway, including formation of LC3B puncta, LC3BII/I ratio, p62 expression, and autophagosomal turnover. Because cytoplasmic LC3 is processed and recruited to the autophagosomal membranes, it is possible to identify cells under- 
A

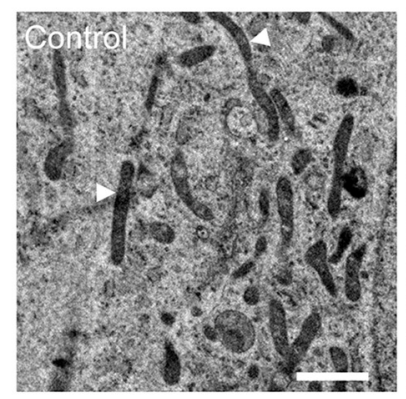

C

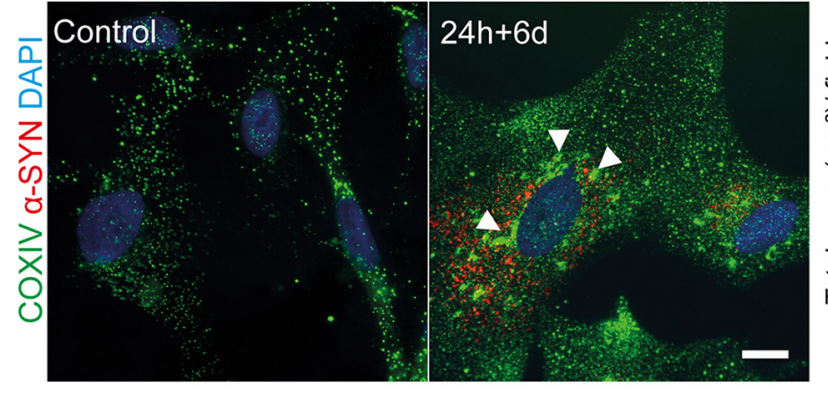

B

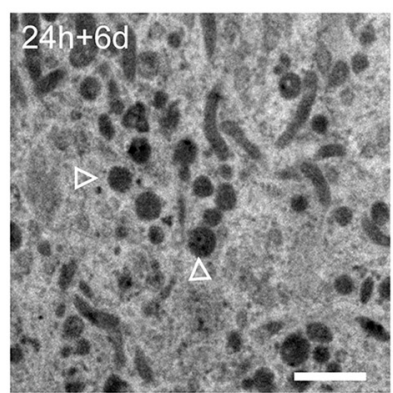

D

D

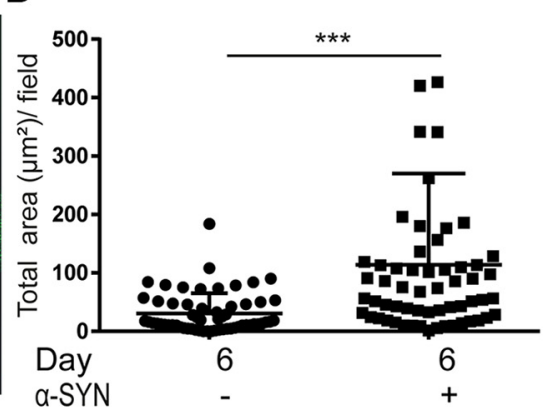

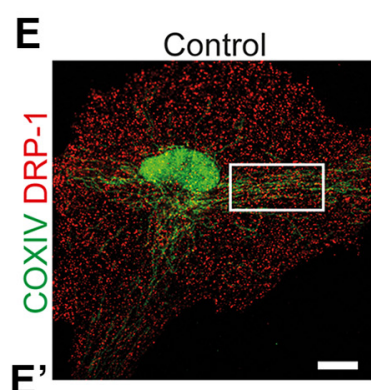
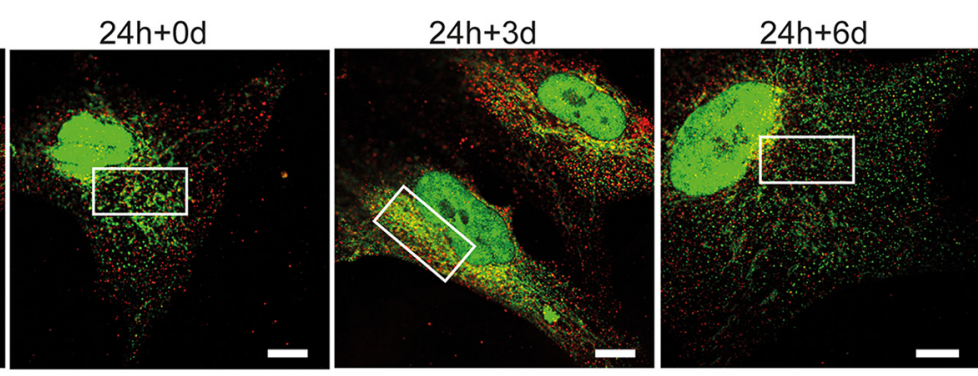

E
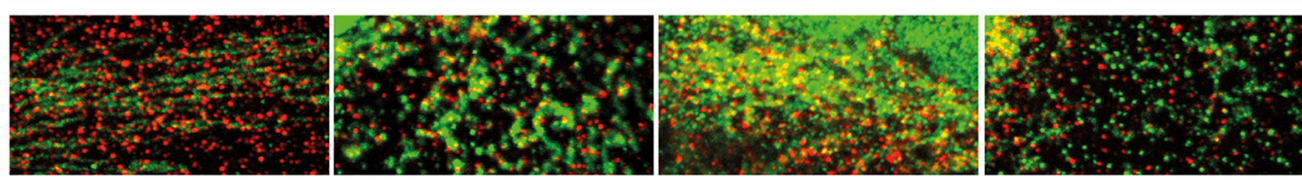

F

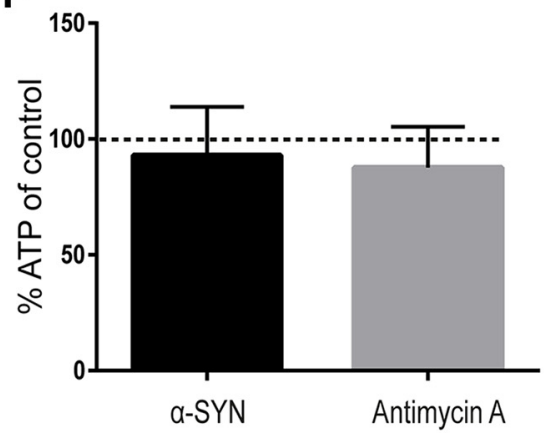

Figure 6. Accumulation of $\alpha$-SYN oligomers results in mitochondrial defects and autophagy dysfunction. TEM analysis showed widespread mitochondrial fragmentation in $\alpha$-SYN oligomerexposed astrocytes compared with control cells $(\boldsymbol{A})$ (white arrowheads indicate normal mitochondria and empty arrowheads indicate dense/fragmented mitochondria). Quantification of the percentage of normal mitochondria versus dense/fragmented mitochondria using ImageJ demonstrated a significant increase of dense mitochondria in oligomer-exposed cultures ( $\boldsymbol{B})$. Immunostaining with COXIV antibody demonstrated increased formation of mitochondria aggregates ( $C$ and Fig. 6-1A, available at https://doi.org/10.1523/JNEUROSCI.0983-17.2017.f6-1, white arrowheads). The increased area of the mitochondria aggregates was confirmed by quantification using ImageJ analysis (D). Double staining with specific antibodies to COX IV and DRP-1 followed by confocal imaging displayed an organized pattern of mitochondria and the fission-regulating protein DRP-1 $3 \mathrm{~d}$ after $\alpha$-SYN oligomer exposure ( $24 \mathrm{~h}+3 \mathrm{~d}$ ), preceding an excessive amount of fragmented mitochondria at day $6(24 \mathrm{~h}+6 \mathrm{~d})\left(\boldsymbol{E}\right.$ and Fig. 6-1B, available at https://doi.org/10.1523/JNEUROSCl.0983-17.2017.f6-1). Close-ups of the white rectangles are shown in $\boldsymbol{E}^{\prime}$. ATP measurement showed only a very moderate decrease (7\%) in ATP levels after $\alpha$-SYN oligomer treatment. In control cultures treated with the electron transport inhibitor antimycin A, there was also a very low decrease in ATP levels (13\%) compared with untreated cultures $(\boldsymbol{F})$. Scale bars: $\boldsymbol{A}, 1 \mu \mathrm{m} ; \boldsymbol{C}, \boldsymbol{E}, 20 \mu \mathrm{m}$. Data are presented as mean \pm SD from $14 \alpha$-SYN oligomer-exposed and 12 control astrocytes $(\boldsymbol{B})$ and as mean \pm SD from three independent experiments $(\boldsymbol{D})$. The levels of significance were set to ${ }^{*} p<0.05,{ }^{* *} p<0.01$, and ${ }^{* * *} p<0.001(\boldsymbol{B}, \boldsymbol{D})$. 
A

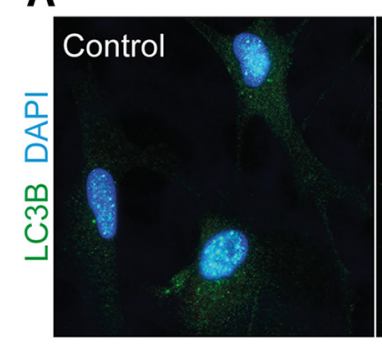

B

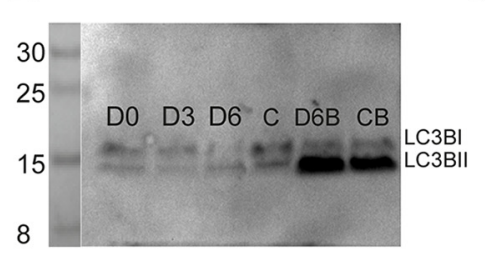

D

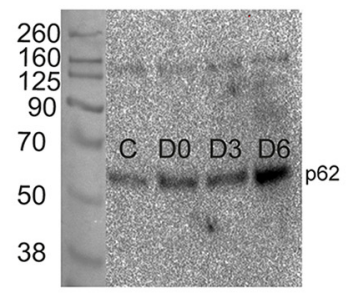

F Control

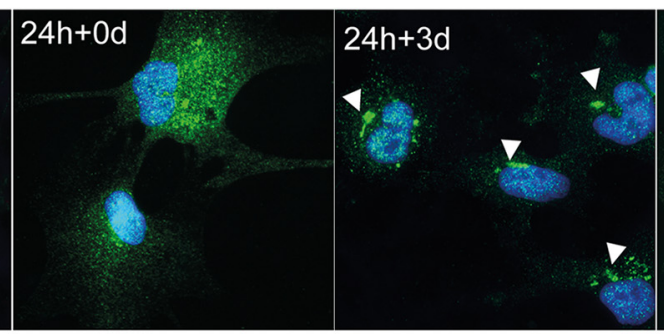

$24 h+6 d$

C

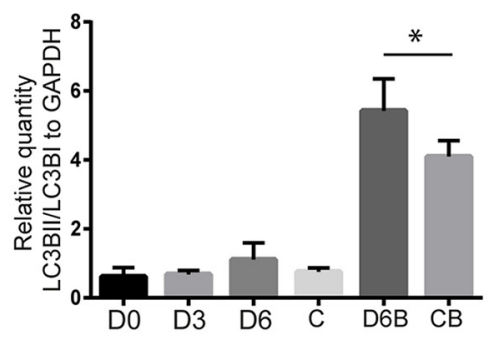

E

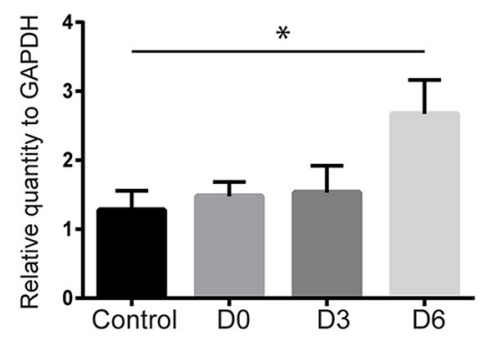

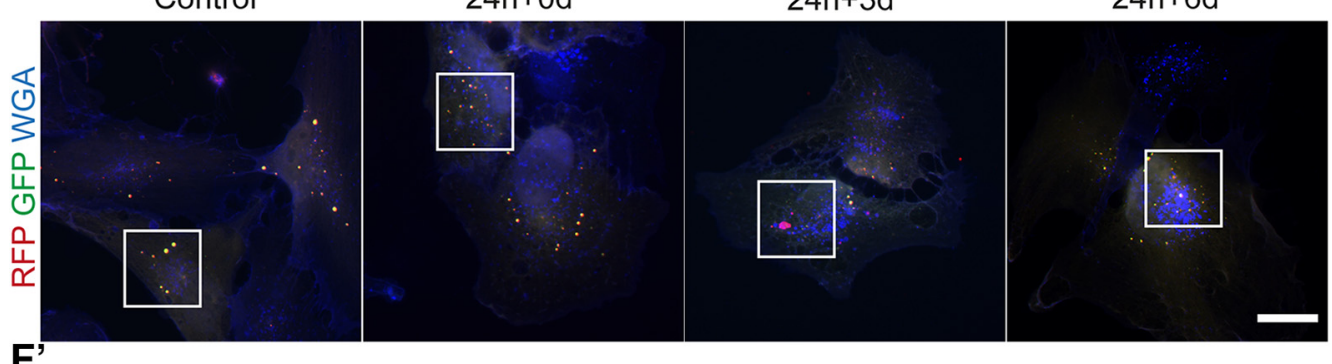

F

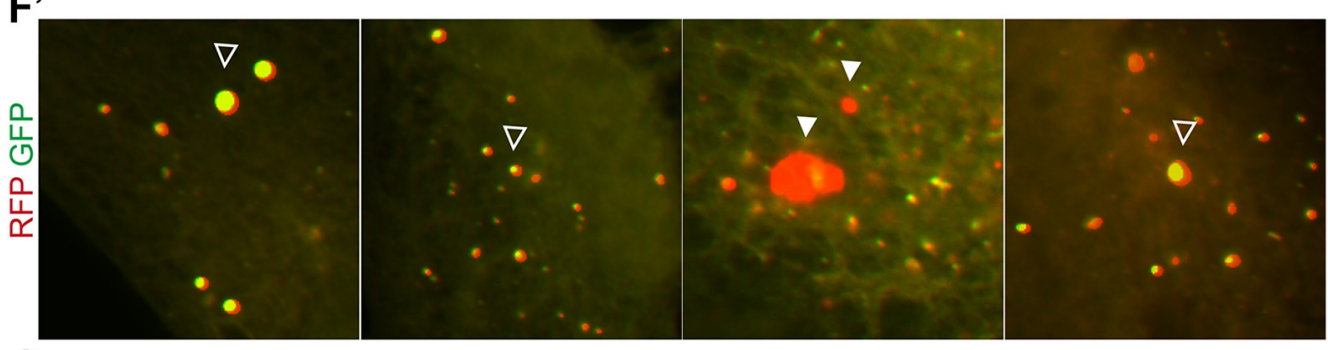

G

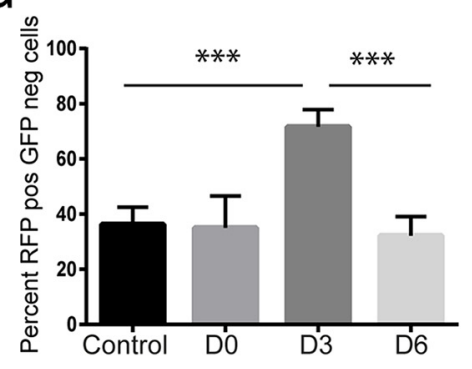

Figure 7. $\alpha$-SYN oligomer exposure affects the autophagosomal pathway. Immunostainings with specific antibodies to the autophagy marker LC3B showed an increased presence of LC3B puncta after $\alpha$-SYN oligomer exposure $(24 \mathrm{~h}+0$ and $24 \mathrm{~h}+3 \mathrm{~d})$ compared with untreated control cultures $(\boldsymbol{A})$. Western blot analysis of $L C 3 B \mathrm{~B}$ and $I I$ showed a significantly increased $\mathrm{LC} 3 \mathrm{BII} / \mathrm{I}$ ratio (normalized to GAPDH) at $24 \mathrm{~h}+6 \mathrm{~d}$ when the cells were treated with the inhibitor bafilomycin A, suggesting a partial block of the autophagosomal machinery by the $\alpha$-SYN oligomers ( $\boldsymbol{B}$, $\boldsymbol{C}$. Western blot analysis of p62 showed a significant increased protein expression at day 6 after oligomer exposure ( $24 \mathrm{~h}+6 \mathrm{~d})$ compared with untreated controls, (Figure legend continues.) 
going autophagy by visualizing fluorescently labeled LC3 puncta. We could indeed identify the formation of $\mathrm{LC}^{+}$puncta in $\alpha \mathrm{SYN}$-treated cultures (Fig. 7A). Interestingly, by day 6, the autophagosomes were reduced to normal levels, indicating that the autophagosomal pathway was initially induced but then halted, although the fragmented mitochondria were still present (Fig. $7 A$ ). To investigate whether $\alpha$-SYN oligomer exposure affects autolysosomal formation and degradation, cells were exposed to bafilomycin A, which inhibits the formation of the autolysosome and neutralizes the lysosomal $\mathrm{pH}$, leading to less degradation. This treatment will then cause accumulation of the LC3II and p62 proteins because the proteins will not be degraded by the autolysosomes. Interestingly, the $\alpha$-SYN and bafilomycin-treated cells showed a significantly higher LC3II/I ratio compared with cultures treated with bafilomycin only. These data demonstrate that the $\alpha \mathrm{SYN}$ oligomers interfere with the autophagosome/lysosome fusion and partially block the autophagic flux (Klionsky et al., 2016; Fig. $7 B, C$ ). Furthermore, Western blot analysis showed a significant increase in the expression of p62 in astrocyte cultures at day 6 after $\alpha \mathrm{SYN}$ oligomer exposure, indicating that the $\alpha \mathrm{SYN}$ oligomers interfere with the autophagosome/lysosome fusion, which is in consistent with the LC3II results (Fig. $7 C, D$ ). Using an autophagy tandem sensor RFP-GFP kit, we transfected the astrocytes with plasmids containing the LC3B gene coupled to RFPand $\mathrm{pH}$-sensitive GFP. This technique makes it possible to follow the turnover of autophagosomes to autolysosomes because the GFP protein is degraded when it comes into contact with low $\mathrm{pH}$. Interestingly, we found a significantly higher number of astrocytes with $\mathrm{RFP}^{+}$but $\mathrm{GFP}^{-}$vesicles at day 3 after $\alpha \mathrm{SYN}$ oligomer exposure, demonstrating that there is an upregulation of autolysosome formation at this time point. However, at day 6 after $\alpha \mathrm{SYN}$ oligomer exposure, the number of astrocytes with $\mathrm{RFP}^{+}$ $\mathrm{GFP}^{-}$vesicles were similar to control cultures (Fig. $7 \mathrm{~F}-\mathrm{H}$ and Fig. 7-1, available at https://doi.org/10.1523/JNEUROSCI. 1005-17.2017.f7-1). Together, these results suggest that the $\alpha$-SYN oligomer exposure induces activation of the autophagosomal machinery, but that the autophagy is discontinued even though the degradation is not completed.

\section{Healthy astrocytes transmit mitochondria to stressed $\alpha-\mathrm{SYN}-$ containing astrocytes}

It was shown recently that mitochondria could transfer via TNTs to rescue "injured" cells (Wang and Gerdes, 2015). Due to the supporting nature of astrocytes in the brain, we wanted to test whether this phenomenon also takes place in $\alpha$-SYN oligomerexposed human astrocytes. By labeling the mitochondria with Mitotracker, we could identify transfer of mitochondria between the astrocytes in $\alpha$-SYN-treated cultures (Fig. 8A). Next, we sought to investigate whether healthy astrocytes could transfer mitochondria to $\alpha$-SYN oligomer-exposed astrocytes. To this end, we performed two different coculture experiments. In one setup, RFP-expressing astrocytes (acceptor cells) were cocultured

\section{$\leftarrow$}

(Figure legend continued.) $(n=3)(\boldsymbol{D}, \boldsymbol{E})$. Next, astrocytes were transfected with plasmids containing the LC3B gene coupled to RFP and pH-sensitive GFP. This autophagy tandem sensor RFP-GFP technique makes it possible to follow the turnover of autophagosomes to autolysosomes because the GFP protein is degraded when it comes into contact with low $\mathrm{pH}$. Representative images from the staining demonstrate that significantly more cells with RFP ${ }^{+}$but $\mathrm{GFP}^{-}$autophagosomes were present at $24 \mathrm{~h}+3 \mathrm{~d}$ compared with untreated control cultures ( $\boldsymbol{F}-\boldsymbol{H}$ and Fig. 7-1, available at https://doi.org/10.1523/JNEUROSCI.0983-17.2017.f7-1) Filled arrowheads indicate $\mathrm{RFP}^{+} \mathrm{GPP}^{-}$vesicles and empty arrowheads indicate $\mathrm{RFP}{ }^{+} \mathrm{GPP}^{+}$vesicles. Scale bars: $\boldsymbol{A}, \boldsymbol{E}, 20 \mu \mathrm{m}$. Data are presented as mean \pm SD. with Mitotracker-labeled, $\alpha$-SYN oligomer-exposed astrocytes (donor cells) (Fig. 8B). In the other setup, $\alpha$-SYN oligomerexposed astrocytes (acceptor cells) were cocultured with RFPexpressing, Mitotracker-labeled astrocytes (donor cells) (Fig. $8 C$ ). Using this approach, we could clearly identify transfer of Mitotracker-labeled mitochondria between the untreated and the $\alpha$-SYN oligomer-exposed astrocytes via both direct transfer (Fig. 8D) and TNTs (Fig. 8E). Quantification of the number of acceptor cells in both experimental setups indicated that the healthy astrocytes transferred significantly more mitochondria to $\alpha$-SYN oligomer-exposed cells than the other way around (Fig. $8 F, p<0.05)$. The addition of latrunculin B to the cocultures resulted in a $>2$-fold decrease in the number of acceptor astrocytes (Fig. $8 G, p<0.001$ ). In cocultures in which neither the acceptor cells nor the donor cells were treated with $\alpha$-SYN oligomers, the level of mitochondrial transfer was significantly lower than in $\alpha$-SYN oligomer-exposed cultures $(p<0.001$ ) (Fig. 8-1, available at https://doi.org/10.1523/JNEUROSCI.0983-17.2017.f8-1).

\section{Discussion}

Compelling experimental data suggest that the transfer of toxic $\alpha$-SYN species from affected cells to healthy cells results in the anatomical spread of pathology seen during PD progression ( Recasens and Dehay, 2014). However, the cell types responsible for the $\alpha$-SYN propagation and the exact transmission mechanisms remain to be elucidated. In a recent study, Abounit et al. (2016) demonstrated that preformed $\alpha$-SYN fibrils could transfer between cultured mouse neurons via TNTs. However, no study has yet demonstrated whether such transfer occurs directly between bona fide human glia or human neurons and human glia. Here, we report for the first time that aggregated $\alpha$-SYN can be transferred between human astrocytes via direct contact and newly formed TNTs and that this transfer can be abrogated using the pharmacological agent latrunculin B. Previous evidence for TNTs in intercellular transfer of misfolded proteins comes primarily from studies of prion diseases (Gousset et al., 2009). For example, the prion protein $(\mathrm{PrP})$ can spread from infected to uninfected neurons or from dendritic cells to uninfected neurons (Gousset et al., 2009). Interestingly, astrocytes that display early PrP accumulation in affected brains have been shown to transfer PrP effectively to uninfected neurons via cell-to-cell contact (Victoria et al., 2016). In addition to PrP, TNT-mediated transfer of $\mathrm{A} \beta$ has been demonstrated to occur between primary rodent astrocytes (Wang et al., 2011).

Increasing evidence emphasizes that insufficient lysosomal degradation is involved in the pathogenesis of different neurodegenerative diseases, including PD (Nixon, 2007; Nixon et al., 2008; Appelqvist et al., 2013). Accordingly, it is known that patients with lysosomal storage disorders (LSDs) often develop neurodegenerative diseases (Nixon, 2007; Appelqvist et al., 2013). For LSDs such as multiple sulfatase deficiency and Gaucher disease, it has been shown that normal autophagic, endocytic, and lysosomal vesicle trafficking can be essential for preventing neurodegeneration (Mazzulli et al., 2011; Di Malta et al., 2012). Here, we show that $\alpha$-SYN oligomers, after engulfment by human astrocytes, colocalized with the endosomal-lysosomal marker LAMP-1. However, although the intracellular deposits of ingested $\alpha$-SYN oligomers persisted, the colocalization with LAMP-1 declined drastically over time. In contrast to the oligomers, $\alpha$-SYN monomers became fully degraded by the human astrocytes. These observations raised the question of whether the oligomers affect the lysosomal machinery directly or if the $\alpha$-SYN accumulation is due to an overall slow degradation of heavily 
A

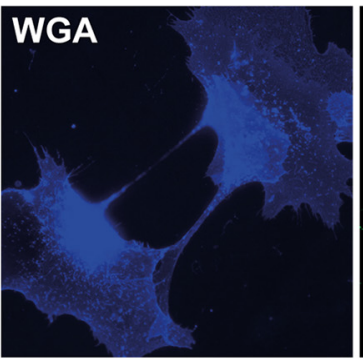

B

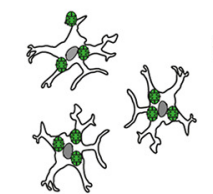

a-SYN exposed mitotracker labe

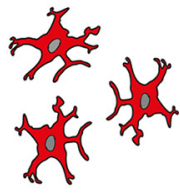

GFAP:tRFP

donor cells

D

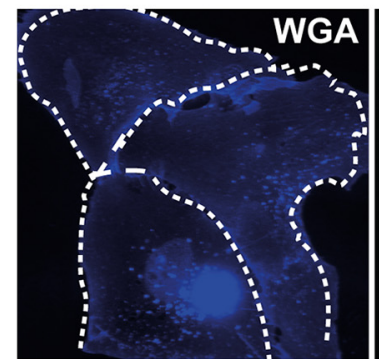

E

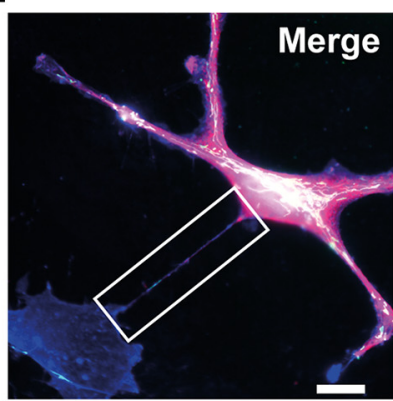

F

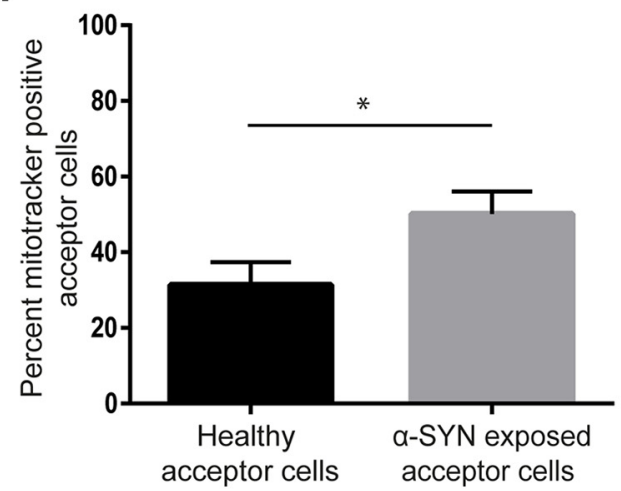
labelled healthy

E'
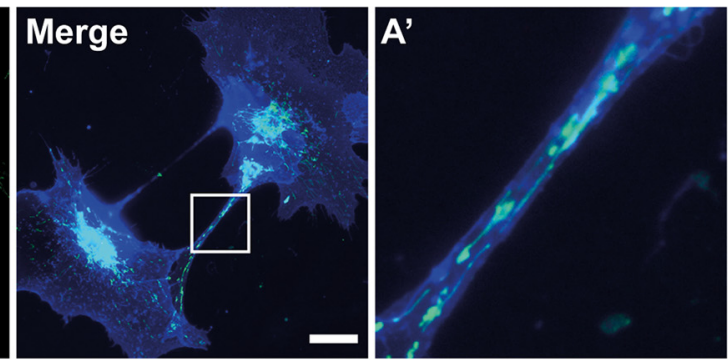

C

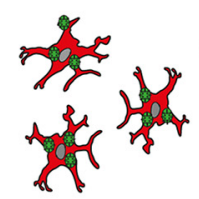

GFAP::tRFP mitotracker labelle donor cells

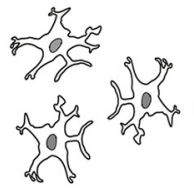

Unlabelled $\alpha-S Y N$ exposed acceptor cells

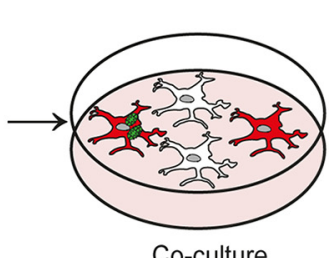

Co-culture
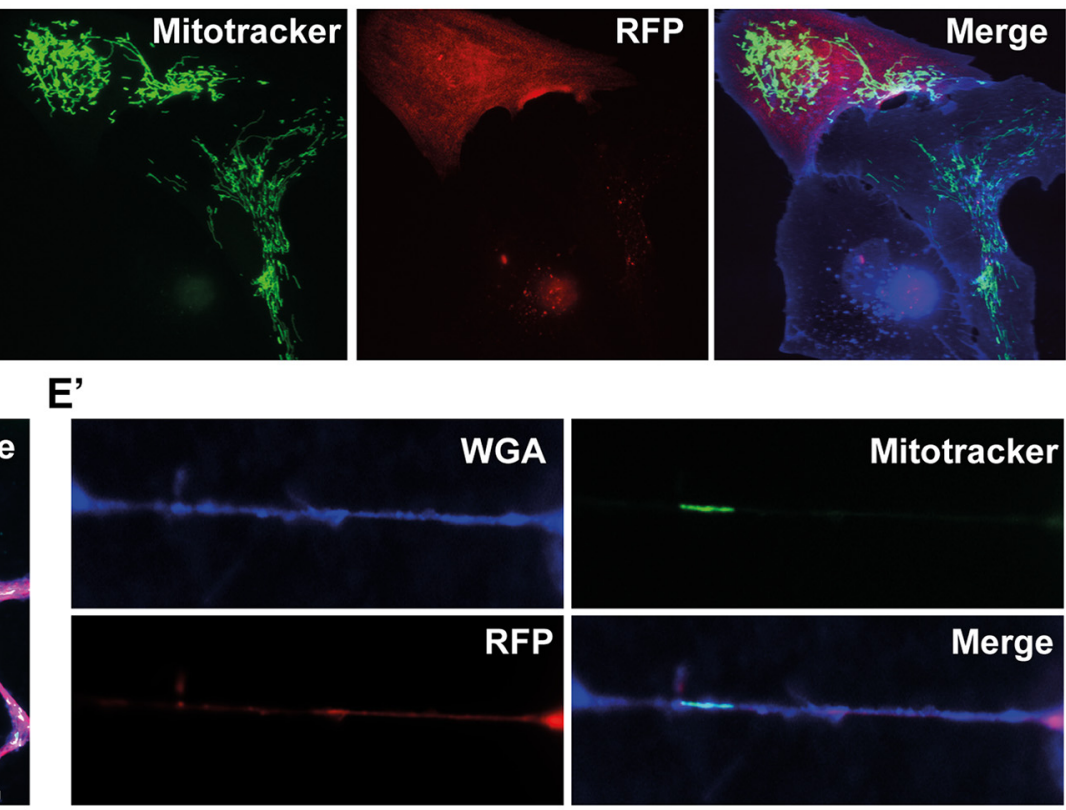

G

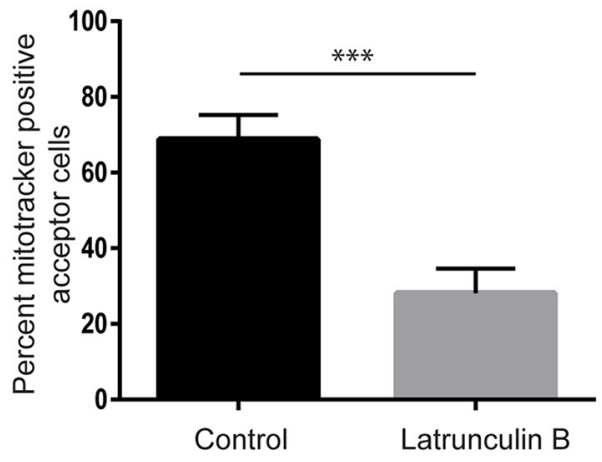

Figure 8. Healthy astrocytes deliver mitochondria to $\alpha$-SYN oligomer-exposed astrocytes. Using Mitotracker transfection, we could demonstrate that mitochondria were present within TNTs connecting the astrocytes $(\boldsymbol{A})$. A close-up of the white rectangle is shown in $\boldsymbol{A}^{\prime}$. Coculture experiments were performed using two different set-ups. Either, GFAP::tRFP astrocytes (red acceptor cells) were cocultured with Mitotracker-transfected, $\alpha$-SYN oligomer-exposed astrocytes (donor cells) (B) or $\alpha$-SYN oligomer-exposed astrocytes (acceptor cells) were cocultured with GFAP::tRFP, Mitotracker-transfected astrocytes (red donor cells) (C). Using immunocytochemistry, we identified transfer of mitochondria between the GFAP::tRFP astrocytes and the unlabeled astrocytes via direct contact (dashed areas show the outline of separate cells) $(\boldsymbol{D})$ and TNTs $(\boldsymbol{E})$, a close-up of the white rectangle is shown in $\boldsymbol{E}^{\prime}$. Quantification of the number of (Figure legend continues.) 


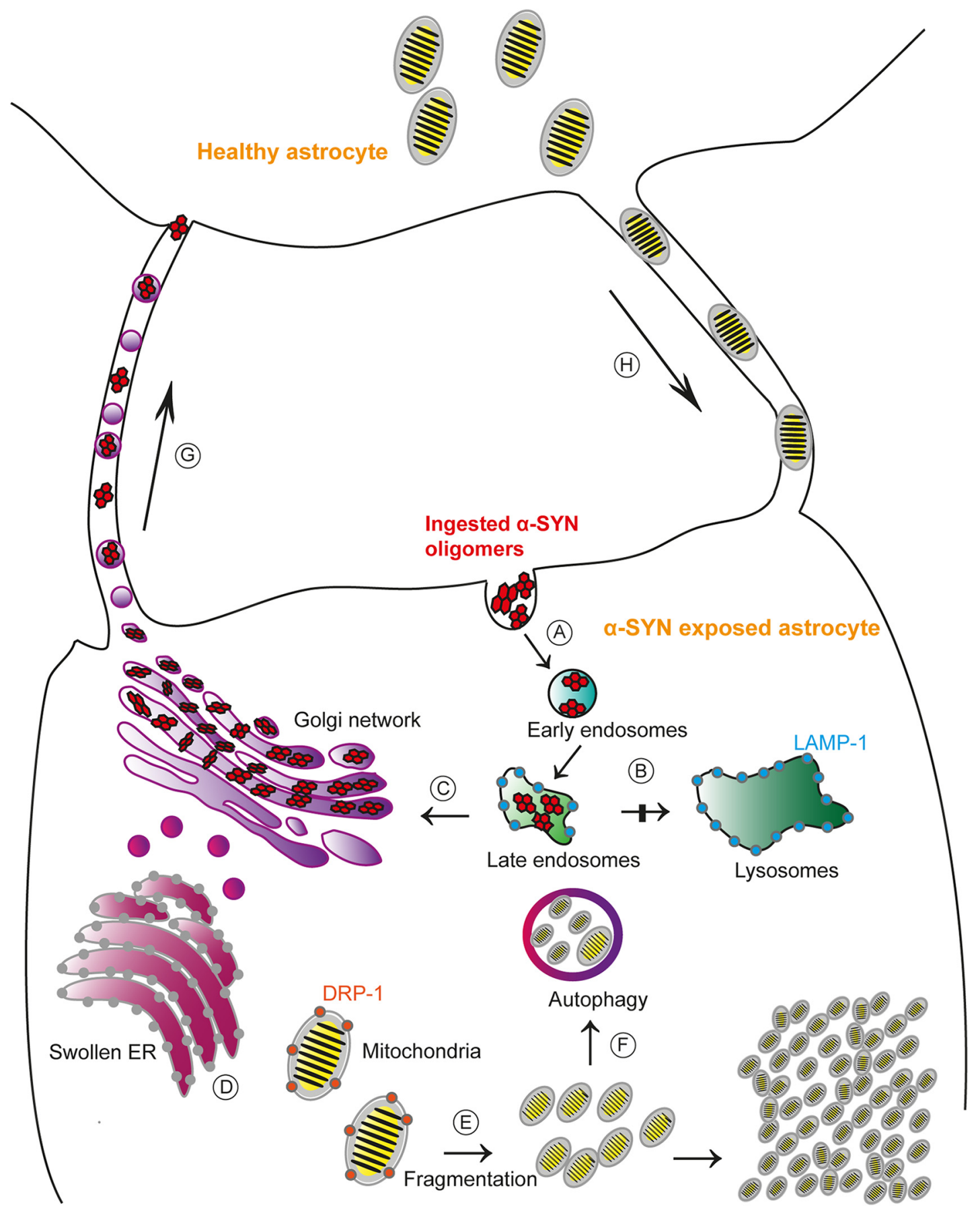

Figure 9. Proposed model for the cellular effects of $\alpha$-SYN accumulation in astrocytes. Ingested $\alpha$-SYN oligomers are transported to early/late endsosomes ( $A$ ), but the lysosomal degradation is not completed $(\boldsymbol{B})$. Instead, the aggregated $\alpha$-SYN is stored intracellularly in the TGN region (C). The $\alpha$-SYN accumulation is clearly stressful for the cell and results in swollen ER (D) and mitochondria fragmentation $(\boldsymbol{E})$. Impaired mitochondria are initially degraded by the autophagosomes $(\boldsymbol{F})$. However, the mitophagy is insufficient and pathological mitochondria remain in the astrocyte. Moreover, $\alpha$-SYN oligomer-exposed astrocytes rapidly deploy a "defense mechanism" that consists of sending out TNTs to other astrocytes, enabling direct intercellular transmission of the toxic protein to healthy astrocytes $(\boldsymbol{G})$. In return, healthy astrocytes send mitochondria to "rescue" stressed astrocytes $(\boldsymbol{H})$.

(Figure legend continued.) Mitotracker ${ }^{+}$acceptor cells in the two coculture setups indicated that the healthy astrocytes transferred significantly more mitochondria to $\alpha$-SYN oligomer-exposed cells than the other way around $(\boldsymbol{F})$. Addition of latrunculin B to the cocultures significantly decreased the percentage of Mitotracker ${ }^{+}$acceptor cells (G). In addition, basal level of mitochondrial transfer was investigated in untreated control cultures. Compared with $\alpha$-SYN oligomer-exposed cultures, the number of Mitotracker ${ }^{+}$acceptor cells was significantly lower in the control cultures (see Fig. 8-1, available at https://doi.org/10.1523/JNEUROSCI.0983-17.2017.f8-1). Scale bars: $\boldsymbol{A}, 20 \mu \mathrm{m} ; \boldsymbol{D}, \boldsymbol{E}, 20$ $\mu \mathrm{m}$. Data are presented as mean \pm SEM from three independent experiments and the levels of significance were set to ${ }^{*} p<0.05,{ }^{* *} p<0.01$, and ${ }^{* * *} p<0.001(\boldsymbol{F}, \boldsymbol{G})$. compacted material by the astrocytes. Our observations, together with previous studies, indicate that it is probably a combination of both.

We have demonstrated previously that astrocytes engulf large amounts of aggregated $\mathrm{A} \beta_{42}$ that are stored in the cells for a very long time (Söllvander et al., 2016). Similarly, we have shown that astrocytes effectively engulf dead cells both in vitro and in vivo and they are degraded very slowly (Lööv et al., 2012). A general slow digestion in astrocytes may be explained by their antigen presen- 
tation properties. Several studies have suggested that astrocytes are involved in T-cell activation because they express major histocompatibility complex class II (Cornet et al., 2000; Lööv et al., 2015). Accordingly, T-cell infiltration has been observed in the $\mathrm{PD}$ brain at advanced disease stages. Conversely, aggregated $\alpha$-SYN has been shown to affect lysosomal function by inhibiting the activity of lysosomal enzymes (Mazzulli et al., 2011). Interestingly, lysosomal dysfunction in SH-SY5Y cells increases $\alpha$-SYN release via exosomes (Alvarez-Erviti et al., 2011). Moreover, a recent study demonstrated that lysosomes containing preformed $\alpha$-SYN fibrils can transfer between neuronal cells (Abounit et al., 2016). In this study, we did not observe any intercellular transfer of $\alpha$-SYN situated within lysosomes, which could be explained by the fact that astrocytes store the $\alpha$-SYN in LAMP- $1^{-}$compartments. The incomplete degradation of ingested $\alpha$-SYN oligomers in human astrocytes leads to intracellular accumulation in the TGN region. Retrograde transport of proteins from endosomes to the TGN is a well known phenomenon (Bonifacino and Rojas, 2006). Localization of $\alpha$-SYN deposits in TGN has been demonstrated previously to cause Golgi fragmentation, impaired vesicular transport, blockage of ER-Golgi transport (Cooper et al., 2006), and lysosomal dysfunction in dopaminergic neurons (Mazzulli et al., 2016). The $\alpha$-SYN oligomer-exposed human astrocytes showed no signs of Golgi fragmentation or increased apoptosis, but displayed severe ER swelling and autophagy disturbances, as well as mitochondria impairment, indicating that the astrocytes were substantially stressed.

There have been several hypotheses about how $\alpha$-SYN aggregates induce mitochondrial dysfunction in neurons. Among these, disturbance of the mitochondria fission-fusion hemostasis, autophagososme synthesis, and mitophagy function in particular has been highlighted (Gui et al., 2012; Nakamura, 2013; GuardiaLaguarta et al., 2014; Ryan et al., 2015). A functional autophagosomal pathway is highly relevant to prevent neurodegeneration because it is a key route for the degradation of a range of intracytoplasmic aggregate-prone proteins and is also a disposal route for dysfunctional mitochondria. Our data demonstrate a widespread mitochondrial fragmentation in the $\alpha$-SYN-treated astrocytes and suggest that the accumulation of $\alpha$-SYN aggregates in the TGN region may disrupt the autophagosomal and mitophagy machinery because the autophagosomal membranes are provided by the ER and Golgi. Moreover, our examinations of various steps in their autophagosomal pathway indicate that autophagy is induced but then halted, although the fragmented mitochondria are still present. These findings indicate that the accumulation of $\alpha$-SYN in the astrocytes disrupts their lysosomal machinery and prevents clearance of the damaged mitochondria. Consistent with our findings, it has been shown previously that overexpression of $\alpha$-SYN can inhibit autophagosome formation (Winslow et al., 2010).

As a consequence of the ineffective degradation of $\alpha$-SYN oligomers and mitochondrial disturbances, the stressed astrocytes deploy a "defense mechanism" that consists of sending out TNTs to other astrocytes, enabling direct intercellular transfer of the toxic protein to healthy astrocytes. In return, healthy astrocytes send mitochondria to rescue the stressed, $\alpha$-SYN-accumulating astrocytes, suggesting that astrocytes naturally help each other by compensating for protein aggregation and cellular stress with new energy-producing mitochondria. This finding is consistent with earlier observations that TNT-mediated transfer of mitochondria from healthy cells can rescue UV-treated cells from apoptosis (Spees et al., 2006; Wang and Gerdes, 2015; Han et al., 2016; Jiang et al., 2016). Moreover, it was shown recently that mesenchymal stem cells can transfer their mitochondria to macrophages via TNTs and thereby enhance macrophage phagocytosis of bacteria (Jackson et al., 2016).

Neurodegenerative diseases, including PD, are defined by loss of brain homeostasis (Giaume et al., 2007; Coulter and Eid, 2012; Verkhratsky et al., 2012; Verkhratsky et al., 2013; Verkhratsky et al., 2015), which could be explained, at least in part, by the fact that severely stressed astrocytes are unable to fulfill their normal tasks (Eroglu and Barres, 2010; Sofroniew and Vinters, 2010; Verkhratsky et al., 2015). In conclusion, our data show that high loads of $\alpha$-SYN in human astrocytes induced ER swelling, lysosomal-autophagosomal dysfunction, and consequently TNTmediated transfer of aggregated $\alpha$-SYN and mitochondria (Fig. 9). Using a pharmacological approach to inhibit TNT formation, we abolished the transfer of both $\alpha$-SYN and mitochondria, identifying astrocytic TNTs as a possible drug target.

\section{References}

Abounit S, Bousset L, Loria F, Zhu S, de Chaumont F, Pieri L, Olivo-Marin JC, Melki R, Zurzolo C (2016) Tunneling nanotubes spread fibrillar alphasynuclein by intercellular trafficking of lysosomes. EMBO J 35:2120 2138. CrossRef Medline

Alvarez-Erviti L, Seow Y, Schapira AH, Gardiner C, Sargent IL, Wood MJ, Cooper JM (2011) Lysosomal dysfunction increases exosome-mediated alpha-synuclein release and transmission. Neurobiol Dis 42:360-367. CrossRef Medline

Appelqvist H, Wäster P, Kågedal K, Öllinger K (2013) The lysosome: from waste bag to potential therapeutic target. J Mol Cell Biol 5:214-226. CrossRef Medline

Bonifacino JS, Rojas R (2006) Retrograde transport from endosomes to the trans-Golgi network. Nat Rev Mol Cell Biol 7:568-579. CrossRef Medline

Braak H, Sastre M, Del Tredici K (2007) Development of alpha-synuclein immunoreactive astrocytes in the forebrain parallels stages of intraneuronal pathology in sporadic Parkinson's disease. Acta Neuropathol 114: 231-241. CrossRef Medline

Bukoreshtliev NV, Wang X, Hodneland E, Gurke S, Barroso JF, Gerdes HH (2009) Selective block of tunneling nanotube (TNT) formation inhibits intercellular organelle transfer between PC12 cells. FEBS Lett 583:14811488. CrossRef Medline

Chang GH, Barbaro NM, Pieper RO (2000) Phosphatidylserine-dependent phagocytosis of apoptotic glioma cells by normal human microglia, astrocytes, and glioma cells. Neuro Oncol 2:174-183. Medline

Chinta SJ, Mallajosyula JK, Rane A, Andersen JK (2010) Mitochondrial alpha-synuclein accumulation impairs complex I function in dopaminergic neurons and results in increased mitophagy in vivo. Neurosci Lett 486:235-239. CrossRef Medline

Chung WS, Clarke LE, Wang GX, Stafford BK, Sher A, Chakraborty C, Joung J, Foo LC, Thompson A, Chen C, Smith SJ, Barres BA (2013) Astrocytes mediate synapse elimination through MEGF10 and MERTK pathways. Nature 504:394-400. CrossRef Medline

Cooper AA, Gitler AD, Cashikar A, Haynes CM, Hill KJ, Bhullar B, Liu K, Xu K, Strathearn KE, Liu F, Cao S, Caldwell KA, Caldwell GA, Marsischky G, Kolodner RD, Labaer J, Rochet JC, Bonini NM, Lindquist S (2006) Alpha-synuclein blocks ER-Golgi traffic and Rab1 rescues neuron loss in Parkinson's models. Science 313:324-328. CrossRef Medline

Cornet A, Bettelli E, Oukka M, Cambouris C, Avellana-Adalid V, Kosmatopoulos K, Liblau RS (2000) Role of astrocytes in antigen presentation and naive T-cell activation. J Neuroimmunol 106:69-77. CrossRef Medline

Coulter DA, Eid T (2012) Astrocytic regulation of glutamate homeostasis in epilepsy. Glia 60:1215-1226. CrossRef Medline

Croisier E, Graeber MB (2006) Glial degeneration and reactive gliosis in alpha-synucleinopathies: the emerging concept of primary gliodegeneration. Acta Neuropathol 112:517-530. CrossRef Medline

Danzer KM, Haasen D, Karow AR, Moussaud S, Habeck M, Giese A, Kretzschmar H, Hengerer B, Kostka M (2007) Different species of alphasynuclein oligomers induce calcium influx and seeding. J Neurosci 27: 9220-9232. CrossRef Medline

Danzer KM, Ruf WP, Putcha P, Joyner D, Hashimoto T, Glabe C, Hyman BT, 
McLean PJ (2011) Heat-shock protein 70 modulates toxic extracellular alpha-synuclein oligomers and rescues trans-synaptic toxicity. FASEB J 25:326-336. CrossRef Medline

Desplats P, Lee HJ, Bae EJ, Patrick C, Rockenstein E, Crews L, Spencer B, Masliah E, Lee SJ (2009) Inclusion formation and neuronal cell death through neuron-to-neuron transmission of alpha-synuclein. Proc Natl Acad Sci U S A 106:13010-13015. CrossRef Medline

Di Malta C, Fryer JD, Settembre C, Ballabio A (2012) Astrocyte dysfunction triggers neurodegeneration in a lysosomal storage disorder. Proc Natl Acad Sci U S A 109:E2334-2342. CrossRef Medline

Emmanouilidou E, Elenis D, Papasilekas T, Stranjalis G, Gerozissis K, Ioannou PC, Vekrellis K (2011) Assessment of alpha-synuclein secretion in mouse and human brain parenchyma. PLoS One 6:e22225. CrossRef Medline

Eroglu C, Barres BA (2010) Regulation of synaptic connectivity by glia. Nature 468:223-231. CrossRef Medline

Evans E, Leung A, Zhelev D (1993) Synchrony of cell spreading and contraction force as phagocytes engulf large pathogens. J Cell Biol 122:12951300. CrossRef Medline

Fellner L, Irschick R, Schanda K, Reindl M, Klimaschewski L, Poewe W, Wenning GK, Stefanova N (2013) Toll-like receptor 4 is required for alpha-synuclein dependent activation of microglia and astroglia. Glia 61: 349-360. CrossRef Medline

Giaume C, Kirchhoff F, Matute C, Reichenbach A, Verkhratsky A (2007) Glia: the fulcrum of brain diseases. Cell Death Differ 14:1324-1335. CrossRef Medline

Gousset K, Schiff E, Langevin C, Marijanovic Z, Caputo A, Browman DT, Chenouard N, de Chaumont F, Martino A, Enninga J, Olivo-Marin JC, Männel D, Zurzolo C (2009) Prions hijack tunnelling nanotubes for intercellular spread. Nat Cell Biol 11:328-336. CrossRef Medline

Guardia-Laguarta C, Area-Gomez E, Rüb C, Liu Y, Magrané J, Becker D, Voos W, Schon EA, Przedborski S (2014) alpha-Synuclein is localized to mitochondria-associated ER membranes. J Neurosci 34:249-259. CrossRef Medline

Gui YX, Wang XY, Kang WY, Zhang YJ, Zhang Y, Zhou Y, Quinn TJ, Liu J, Chen SD (2012) Extracellular signal-regulated kinase is involved in alpha-synuclein-induced mitochondrial dynamic disorders by regulating dynamin-like protein 1. Neurobiol Aging 33:2841-2854. CrossRef Medline

Han H, Hu J, Yan Q, Zhu J, Zhu Z, Chen Y, Sun J, Zhang R (2016) Bone marrow-derived mesenchymal stem cells rescue injured $\mathrm{H} 9 \mathrm{c} 2$ cells via transferring intact mitochondria through tunneling nanotubes in an in vitro simulated ischemia/reperfusion model. Mol Med Rep 13:15171524. CrossRef Medline

Hansen C, Angot E, Bergström AL, Steiner JA, Pieri L, Paul G, Outeiro TF, Melki R, Kallunki P, Fog K, Li JY, Brundin P (2011) alpha-Synuclein propagates from mouse brain to grafted dopaminergic neurons and seeds aggregation in cultured human cells. J Clin Invest 121:715-725. CrossRef Medline

Holmqvist S, Brouwer M, Djelloul M, Diaz AG, Devine MJ, Hammarberg A, Fog K, Kunath T, Roybon L (2015) Generation of human pluripotent stem cell reporter lines for the isolation of and reporting on astrocytes generated from ventral midbrain and ventral spinal cord neural progenitors. Stem Cell Res 15:203-220. CrossRef Medline

Jackson MV, Morrison TJ, Doherty DF, McAuley DF, Matthay MA, Kissenpfennig A, O'Kane CM, Krasnodembskaya AD (2016) Mitochondrial transfer via tunneling nanotubes (TNT) is an important mechanism by which mesenchymal stem cells enhance macrophage phagocytosis in the in vitro and in vivo models of ARDS. Stem Cells 34:2210-2223. CrossRef Medline

Jang A, Lee HJ, Suk JE, Jung JW, Kim KP, Lee SJ (2010) Non-classical exocytosis of alpha-synuclein is sensitive to folding states and promoted under stress conditions. J Neurochem 113:1263-1274. CrossRef Medline

Jiang D, Gao F, Zhang Y, Wong DS, Li Q, Tse HF, Xu G, Yu Z, Lian Q (2016) Mitochondrial transfer of mesenchymal stem cells effectively protects corneal epithelial cells from mitochondrial damage. Cell Death Dis 7:e2467. CrossRef Medline

Jones RS, Minogue AM, Connor TJ, Lynch MA (2013) Amyloid-betainduced astrocytic phagocytosis is mediated by CD36, CD47 and RAGE. J Neuroimmune Pharmacol 8:301-311. CrossRef Medline

Katsuragi Y, Ichimura Y, Komatsu M (2015) p62/SQSTM1 functions as a signaling hub and an autophagy adaptor. FEBS J 282:4672-4678. CrossRef Medline
Kimura S, Hase K, Ohno H (2013) The molecular basis of induction and formation of tunneling nanotubes. Cell Tissue Res 352:67-76. CrossRef Medline

Klionsky DJ, et al. (2016) Guidelines for the use and interpretation of assays for monitoring autophagy (3rd edition). Autophagy 12:1-222. CrossRef Medline

Kordower JH, Chu Y, Hauser RA, Freeman TB, Olanow CW (2008) Lewy body-like pathology in long-term embryonic nigral transplants in Parkinson's disease. Nat Med 14:504-506. CrossRef Medline

Lee HJ, Suk JE, Patrick C, Bae EJ, Cho JH, Rho S, Hwang D, Masliah E, Lee SJ (2010) Direct transfer of alpha-synuclein from neuron to astroglia causes inflammatory responses in synucleinopathies. J Biol Chem 285:92629272. CrossRef Medline

Li JY, Englund E, Holton JL, Soulet D, Hagell P, Lees AJ, Lashley T, Quinn NP, Rehncrona S, Björklund A, Widner H, Revesz T, Lindvall O, Brundin P (2008) Lewy bodies in grafted neurons in subjects with Parkinson's disease suggest host-to-graft disease propagation. Nat Med 14:501-503. CrossRef Medline

Lindström V, Gustafsson G, Sanders LH, Howlett EH, Sigvardson J, Kasrayan A, Ingelsson M, Bergström J, Erlandsson A (2017) Extensive uptake of alpha-synuclein oligomers in astrocytes results in sustained intracellular deposits and mitochondrial damage. Mol Cell Neurosci 82:143-156. CrossRef Medline

Lööv C, Hillered L, Ebendal T, Erlandsson A (2012) Engulfing astrocytes protect neurons from contact-induced apoptosis following injury. PLoS One 7:e33090. CrossRef Medline

Lööv C, Mitchell CH, Simonsson M, Erlandsson A (2015) Slow degradation in phagocytic astrocytes can be enhanced by lysosomal acidification. Glia 63:1997-2009. CrossRef Medline

Luth ES, Stavrovskaya IG, Bartels T, Kristal BS, Selkoe DJ (2014) Soluble, prefibrillar alpha-synuclein oligomers promote complex I-dependent, Ca2+-induced mitochondrial dysfunction. J Biol Chem 289:2149021507. CrossRef Medline

Magnus T, Chan A, Linker RA, Toyka KV, Gold R (2002) Astrocytes are less efficient in the removal of apoptotic lymphocytes than microglia cells: implications for the role of glial cells in the inflamed central nervous system. J Neuropathol Exp Neurol 61:760-766. CrossRef Medline

Mazzulli JR, Xu YH, Sun Y, Knight AL, McLean PJ, Caldwell GA, Sidransky E, Grabowski GA, Krainc D (2011) Gaucher disease glucocerebrosidase and alpha-synuclein form a bidirectional pathogenic loop in synucleinopathies. Cell 146:37-52. CrossRef Medline

Mazzulli JR, Zunke F, Isacson O, Studer L, Krainc D (2016) alphaSynuclein-induced lysosomal dysfunction occurs through disruptions in protein trafficking in human midbrain synucleinopathy models. Proc Natl Acad Sci U S A 113:1931-1936. CrossRef Medline

Nakamura K (2013) alpha-Synuclein and mitochondria: partners in crime? Neurotherapeutics 10:391-399. CrossRef Medline

Näsström T, Fagerqvist T, Barbu M, Karlsson M, Nikolajeff F, Kasrayan A, Ekberg M, Lannfelt L, Ingelsson M, Bergström J (2011) The lipid peroxidation products 4-oxo-2-nonenal and 4-hydroxy-2-nonenal promote the formation of alpha-synuclein oligomers with distinct biochemical, morphological, and functional properties. Free Radic Biol Med 50:428437. CrossRef Medline

Nixon RA (2007) Autophagy, amyloidogenesis and Alzheimer disease. J Cell Sci 120:4081-4091. CrossRef Medline

Nixon RA, Yang DS, Lee JH (2008) Neurodegenerative lysosomal disorders: a continuum from development to late age. Autophagy 4:590-599. CrossRef Medline

Ogen-Shtern N, Ben David T, Lederkremer GZ (2016) Protein aggregation and ER stress. Brain Res 1648:658-666. CrossRef Medline

Rappold PM, Tieu K (2010) Astrocytes and therapeutics for Parkinson's disease. Neurotherapeutics 7:413-423. CrossRef Medline

Recasens A, Dehay B (2014) Alpha-synuclein spreading in Parkinson's disease. Front Neuroanat 8:159. CrossRef Medline

Rustom A, Saffrich R, Markovic I, Walther P, Gerdes HH (2004) Nanotubular highways for intercellular organelle transport. Science 303:10071010. CrossRef Medline

Ryan BJ, Hoek S, Fon EA, Wade-Martins R (2015) Mitochondrial dysfunction and mitophagy in Parkinson's: from familial to sporadic disease. Trends Biochem Sci 40:200-210. CrossRef Medline

Sisakhtnezhad S, Khosravi L (2015) Emerging physiological and pathological implications of tunneling nanotubes formation between cells. Eur J Cell Biol 94:429-443. CrossRef Medline 
Sofroniew MV, Vinters HV (2010) Astrocytes: biology and pathology. Acta Neuropathol 119:7-35. CrossRef Medline

Sokolowski JD, Nobles SL, Heffron DS, Park D, Ravichandran KS, Mandell JW (2011) Brain-specific angiogenesis inhibitor-1 expression in astrocytes and neurons: implications for its dual function as an apoptotic engulfment receptor. Brain Behav Immun 25:915-921. CrossRef Medline

Söllvander S, Nikitidou E, Brolin R, Söderberg L, Sehlin D, Lannfelt L, Erlandsson A (2016) Accumulation of amyloid-beta by astrocytes result in enlarged endosomes and microvesicle-induced apoptosis of neurons. Mol Neurodegener 11:38. CrossRef Medline

Spees JL, Olson SD, Whitney MJ, Prockop DJ (2006) Mitochondrial transfer between cells can rescue aerobic respiration. Proc Natl Acad Sci U S A 103:1283-1288. CrossRef Medline

Spillantini MG, Schmidt ML, Lee VM, Trojanowski JQ, Jakes R, Goedert M (1997) Alpha-synuclein in Lewy bodies. Nature 388:839-840. CrossRef Medline

Spillantini MG, Crowther RA, Jakes R, Hasegawa M, Goedert M (1998) alpha-Synuclein in filamentous inclusions of Lewy bodies from Parkinson's disease and dementia with lewy bodies. Proc Natl Acad Sci U S A 95:6469-6473. CrossRef Medline

Terada S, Ishizu H, Yokota O, Tsuchiya K, Nakashima H, Ishihara T, Fujita D, Uéda K, Ikeda K, Kuroda S (2003) Glial involvement in diffuse Lewy body disease. Acta Neuropathol 105:163-169. Medline

Tu PH, Galvin JE, Baba M, Giasson B, Tomita T, Leight S, Nakajo S, Iwatsubo T, Trojanowski JQ, Lee VM (1998) Glial cytoplasmic inclusions in white matter oligodendrocytes of multiple system atrophy brains contain insoluble alpha-synuclein. Ann Neurol 44:415-422. CrossRef Medline

Verkhratsky A, Sofroniew MV, Messing A, deLanerolle NC, Rempe D, Rodriguez JJ, Nedergaard M (2012) Neurological diseases as primary gliopathies: a reassessment of neurocentrism. ASN Neuro 4: pii: e00082. CrossRef Medline

Verkhratsky A, Rodríguez JJ, Parpura V (2013) Astroglia in neurological diseases. Future Neurol 8:149-158. CrossRef Medline
Verkhratsky A, Nedergaard M, Hertz L (2015) Why are astrocytes important? Neurochem Res 40:389-401. CrossRef Medline

Victoria GS, Arkhipenko A, Zhu S, Syan S, Zurzolo C (2016) Astrocyte-toneuron intercellular prion transfer is mediated by cell-cell contact. Sci Rep 6:20762. CrossRef Medline

Wakabayashi K, Hayashi S, Yoshimoto M, Kudo H, Takahashi H (2000) $\mathrm{NACP} /$ alpha-synuclein-positive filamentous inclusions in astrocytes and oligodendrocytes of Parkinson's disease brains. Acta Neuropathol 99:1420. CrossRef Medline

Wang X, Gerdes HH (2015) Transfer of mitochondria via tunneling nanotubes rescues apoptotic PC12 cells. Cell Death Differ 22:1181-1191. CrossRef Medline

Wang X, Bukoreshtliev NV, Gerdes HH (2012) Developing neurons form transient nanotubes facilitating electrical coupling and calcium signaling with distant astrocytes. PLoS One 7:e47429. CrossRef Medline

Wang Y, Cui J, Sun X, Zhang Y (2011) Tunneling-nanotube development in astrocytes depends on p53 activation. Cell Death Differ 18:732-742. CrossRef Medline

Winner B, Jappelli R, Maji SK, Desplats PA, Boyer L, Aigner S, Hetzer C, Loher T, Vilar M, Campioni S, Tzitzilonis C, Soragni A, Jessberger S, Mira H, Consiglio A, Pham E, Masliah E, Gage FH, Riek R (2011) In vivo demonstration that alpha-synuclein oligomers are toxic. Proc Natl Acad Sci U S A 108:4194-4199. CrossRef Medline

Winslow AR, Chen CW, Corrochano S, Acevedo-Arozena A, Gordon DE, Peden AA, Lichtenberg M, Menzies FM, Ravikumar B, Imarisio S, Brown S, O'Kane CJ, Rubinsztein DC (2010) alpha-Synuclein impairs macroautophagy: implications for Parkinson's disease. J Cell Biol 190:10231037. CrossRef Medline

Zhu D, Tan KS, Zhang X, Sun AY, Sun GY, Lee JC (2005) Hydrogen peroxide alters membrane and cytoskeleton properties and increases intercellular connections in astrocytes. J Cell Sci 118:3695-3703. CrossRef Medline 